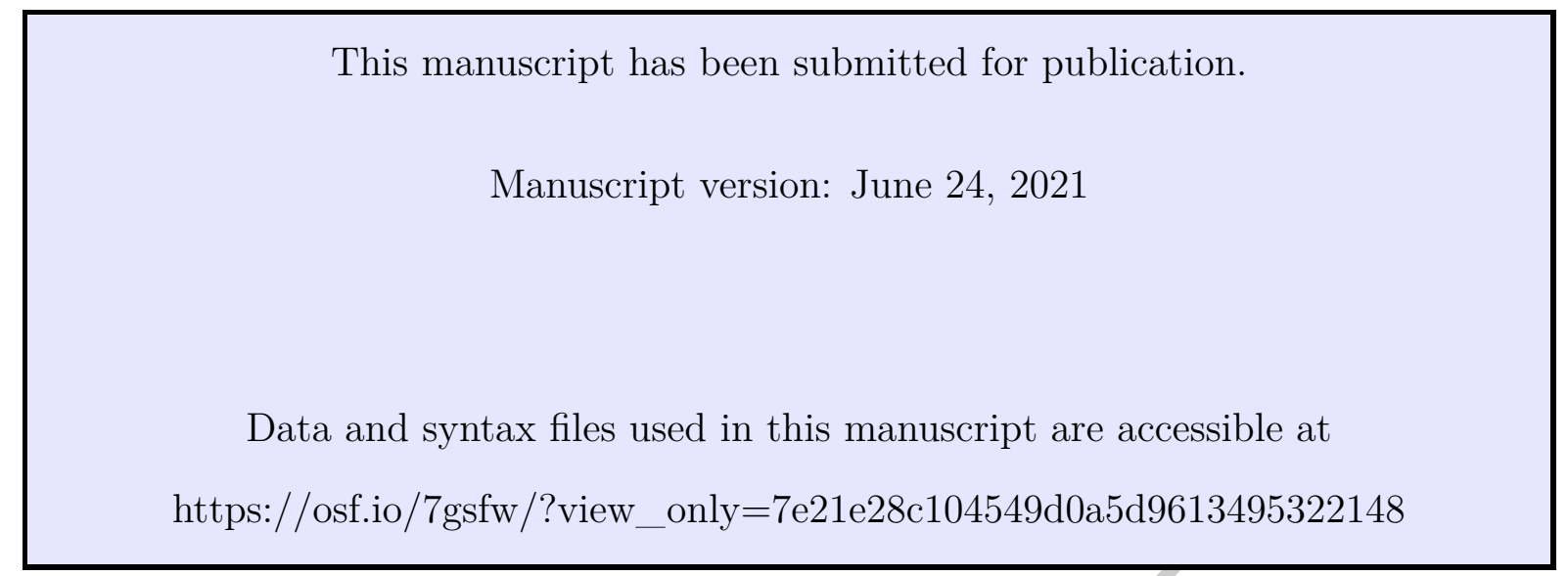


Would the Real Loneliness Please Stand Up? The Validity of Loneliness Measures and the Reliability of Single Items

Marcus Mund ${ }^{1,2}$, Marlies Maes ${ }^{3,4,5}$, Pia M. Drewke², Antonia Gutzeit ${ }^{2}$, Isabel Jaki² , and Pamela Qualter ${ }^{6}$

${ }^{1}$ University of Klagenfurt, Austria

${ }^{2}$ Friedrich-Schiller-Universität Jena, Germany

${ }^{3} \mathrm{KU}$ Leuven, Belgium

${ }^{4}$ Research Foundation-Flanders (FWO), Belgium

${ }^{5}$ Utrecht University, The Netherlands

${ }^{6}$ Manchester Institute of Education, University of Manchester, United Kingdom 


\begin{abstract}
Author Note
Marcus Mund (iD https://orcid.org/0000-0003-0006-9043, University of Klagenfurt, Universitätsstraße 65-67, 9020 Klagenfurt, Austria; Institut für Psychologie, Friedrich-Schiller-Universität Jena, Humboldtstraße 11, D-07743 Jena; Marlies Maes https://orcid.org/0000-0002-1710-5728, School of Psychology and Development in Context, KU Leuven, 3000 Leuven, Belgium; Research Foundation-Flanders (FWO), 1000 Brussels, Belgium; Youth Studies, Utrecht University, 3508 TC Utrecht, The Netherlands; Pia M. Drewke, Antonia Gutzeit, Isabel Jaki, Institut für Psychologie, Friedrich-Schiller-Universität Jena, Humboldtstraße 11, D-07743 Jena; Pamela Qualter (D) https://orcid.org/https://orcid.org/0000-0001-6114-3820, Manchester Institute of Education, The University of Manchester, Manchester M13 9PL, UK.

Correspondence concerning this article should be addressed to Marcus Mund, University of Klagenfurt, Institute of Psychology, Universitätsstraße 65-67, 9020 Klagenfurt, Austria, E-mail: marcus.mund@gmail.com

Preparation of this manuscript was supported by grant DRM/2017-06 from the Friedrich-Schiller-Universität Jena (Study 1) and German Research Foundation grant MU 4338/1-1 (Study 2) awarded to Marcus Mund.
\end{abstract}




\begin{abstract}
Several measures that assess loneliness have been developed for adults. Across three studies, we investigated psychometric features of different versions of the Rasch-Type Loneliness Scale, the UCLA Loneliness Scale, and three single-item measures. In Study 1 ( $\mathrm{N}=697$ self-ratings, $\mathrm{N}=282$ informant-ratings of 163 targets) and Study $2(\mathrm{~N}=$ 1,216 individuals from 608 couples), we investigated the convergent validity and self-informant agreement of the included measures. Furthermore, we compared the nomological nets of these measures using correlates related to demographic aspects, personality, satisfaction, and network characteristics. In Study $3(\mathrm{~N}=411)$, we estimated a reliability of $r_{x x}>.70$ for three single-item measures of loneliness in a short-term prospective study. Overall, all measures and their nomological nets were highly correlated within and across studies, indicating that the included measures are all reliable and valid. Recommendations for choosing a loneliness measure are discussed. Keywords: loneliness, Rasch-Type Loneliness Scale, University of California Los Angeles Loneliness Scale, single-item measures, validity, nomological net, self-other agreement
\end{abstract}




\section{Would the Real Loneliness Please Stand Up? The Validity of Loneliness Measures and the Reliability of Single Items}

Humans are social beings, and they rely and depend on each other (Axelrod \& Hamilton, 1981; Baumeister \& Leary, 1995). Interpersonal relationships are among the most powerful sources for well-being and health (Baumeister \& Leary, 1995; Cohen, 2004; Hartup \& Stevens, 1997; House et al., 1988). When interpersonal relationships are perceived as deficient regarding quantitative (e.g., network size, number of friends) and/or qualitative aspects (e.g., relationship closeness, trust, intimacy), individuals experience loneliness (Ernst \& Cacioppo, 1999; Perlman \& Peplau, 1981).

Since its introduction in the scientific literature by Weiss (1973), loneliness has attracted a lot of attention. The large body of literature that has accumulated is very consistent in demonstrating the negative effects of loneliness on health-related outcomes (for reviews, see Cacioppo et al., 2015; Ernst \& Cacioppo, 1999; Hawkley \& Cacioppo, 2010; Hawkley \& Capitanio, 2015; Heinrich \& Gullone, 2006; Holt-Lunstad et al., 2015) and interpersonal outcomes (Cacioppo et al., 2017; Lodder et al., 2017; Mund \& Johnson, 2021; Mund et al., in press; Spithoven et al., 2018). This consistency is to be highlighted given the multitude of loneliness measures that have been developed over the last decades, including uni- and multidimensional multi-item scales, various abbreviated versions thereof, and a variety of single-item measures. Although issues of validity have been investigated in prior research, these studies are limited in that they (a) have examined either convergent validity between instruments, but not their correlations with external variables (e.g., Cacioppo et al., 2006; Grygiel et al., 2013; Iecovich, 2013; Maes et al., 2017; D. Russell et al., 1980), (b) examined the nomological net of only one or two measures at once (Cacioppo et al., 2006; Shiovitz-Ezra \& Ayalon, 2012; Victor et al., 2005), and, when doing so, (c) mostly only considered demographic variables such as age, gender, and education as external correlates of loneliness (Borys \& Perlman, 1985; Shiovitz-Ezra \& Ayalon, 2012; Victor et al., 2005). Thus, it is unclear whether different loneliness measures for adults tap into different aspects of loneliness or capture a common core. 
In the present study, we extend prior work in four ways. First, we simultaneously examine the convergent validity among, and the nomological net of, the most widely-used measures of loneliness in adulthood (Buecker et al., 2020; Maes et al., 2019; Mund, Freuding, et al., 2020; Pinquart \& Sörensen, 2001): the Rasch-Type Loneliness Scale and its facets emotional and social loneliness (de Jong Gierveld \& Kamphuis, 1985; de Jong Gierveld \& van Tilburg, 2006), the University of California Los Angeles Loneliness Scale in its full (D. Russell et al., 1980; D. Russell et al., 1978; D. W. Russell, 1996) and two abbreviated versions (Hawkley et al., 2015; Hays \& DiMatteo, 1987), and three single-item measures of loneliness. Second, we examine the convergence between self- and informant-ratings of loneliness to extend the assessment of the validity beyond self-reports (McCrae et al., 2004; Podsakoff et al., 2003). Third, in addition to demographic correlates of loneliness, we investigate the nomological net of the various measures using a wide variety of constructs (e.g., Big Five personality traits, domain and life satisfaction, social support, depressiveness, and shyness) to pinpoint similarities and differences between the selected measures. Fourth, we examine the reliability of three single-item measures to investigate the often-raised criticism that such measures lack reliability (D. Russell, 1982).

To achieve these goals, we conducted three independent studies. Studies 1 and 2 were designed to investigate the validity and agreement between self-ratings of close others and examine the nomological nets of different loneliness measures. In Study 3, we examined the reliability of three single-item measures of loneliness using a procedure developed by Heise (1969) in a study extending over three measurement occasions, each two weeks apart.

\section{Measures of Loneliness}

Given its subjective nature (Ernst \& Cacioppo, 1999; Perlman \& Peplau, 1981), loneliness has most often been assessed using self-reports (Marangoni \& Ickes, 1989; D. Russell, 1982). The various self-report measures that have been developed in recent decades primarily differ regarding three aspects (D. Russell, 1982): (a) the dimensionality of the instrument (uni- vs. multidimensional), (b) the number of items 
(i.e., single-item measures vs. multi-item scale), and (c) whether the instrument assesses loneliness in a direct or an indirect way.

\section{Unidimensional and Multidimensional Measures}

Measurement instruments to assess loneliness can be differentiated according to whether they were developed based on the conceptualization of loneliness as a unidimensional construct or as a construct with multiple interrelated facets. Instruments such as the University of California Los Angeles Loneliness Scale (UCLA-LS; D. Russell et al., 1980; D. Russell et al., 1978; D. W. Russell, 1996) have been designed to assess global loneliness. However, it should be noted that some studies have reported specific facets contained in the UCLA-LS (e.g., Hawkley et al., 2005; Maes et al., 2017). As the intent of the authors of the UCLA-LS was to develop a unidimensional scale (D. Russell et al., 1980; D. Russell et al., 1978; D. Russell, 1982; D. W. Russell, 1996), we will treat the scale as unidimensional in the present study.

Other scales such as the Rasch-Type Loneliness Scale (RTLS; de Jong Gierveld \& Kamphuis, 1985; de Jong Gierveld \& van Tilburg, 2006) have been designed to capture multiple aspects of loneliness such as emotional and social loneliness. Multidimensional approaches offer the opportunity to measure loneliness in a more nuanced fashion and to better understand differential predictors and consequences of those facets. However, when taking the RTLS as an example, surprisingly few studies seem to build on its multidimensionality (for meta-analyses, see Buecker et al., 2020; Mund, Freuding, et al., 2020). This might be due to relatively high correlations between the two facets of the RTLS (Grygiel et al., 2013; Iecovich, 2013; Mund \& Neyer, 2016), possibly indicating that the two facets capture actually the same aspects of loneliness. In the present study, we will examine both global loneliness as measured by the RTLS and its facets emotional and social loneliness.

\section{Single Items and Multi-Item Scales}

Single-item measures of loneliness have been used frequently (Mund, Freuding, et al., 2020; Pinquart \& Sörensen, 2001) and have attested substantial content validity (D. Russell, 1982). However, their usage has been discouraged and criticized for several 
reasons (Marangoni \& Ickes, 1989; D. Russell, 1982). For example, the validity of single-item measures has been questioned due to possible socially desirable responding and lack of standardization (Marangoni \& Ickes, 1989; D. Russell, 1982). That is, there is a plethora of single-item measures of loneliness that differ in wording and response format so that it is not fully clear whether all these measures tap into the same construct. Studies comparing single-item with multi-item measures have found a lower prevalence of loneliness when single items are used (Eccles et al., 2020; Victor et al., 2005; but see Shiovitz-Ezra \& Ayalon, 2012, for a contrasting finding). Moreover, it seems that the individuals who are classified as "lonely" based on cut-off scores on multi-item scales are not the same individuals who are classified as "lonely" based on the same cut-off score applied to single-item measures (Eccles et al., 2020; Shiovitz-Ezra \& Ayalon, 2012). Apart from prevalence rates, however, the results obtained with single-item measures converge very well with those obtained with multi-item scales with regard to demographic aspects (Shiovitz-Ezra \& Ayalon, 2012; von Soest et al., 2020), aspects of mean-level and rank-order stability (Mund, Freuding, et al., 2020; Mund, Lüdtke, et al., 2020), interpersonal dynamics (Mund \& Johnson, 2021; Mund et al., in press), personality correlates (Buecker et al., 2020), and health outcomes (Beutel et al., 2017; Eccles et al., 2020), including early mortality (Holt-Lunstad et al., 2015; Shiovitz-Ezra \& Ayalon, 2010).

It has also been argued that single items are unreliable and capture more noise than substantial inter-individual differences (Marangoni \& Ickes, 1989; D. Russell, 1982). In line with this reasoning, a study employing STARTS models (Kenny \& Zautra, 2001) found that single item measures capture more (potentially unreliable) state variance $(\approx 50 \%$ state variance) than longer scales such as a 6 -item version of the RTLS ( $\approx 25 \%$ state variance; Mund, Lüdtke, et al., 2020). However, it has been shown for single-item measures of subjective well-being that state variance can contain a substantial amount of reliable variance (Lucas \& Donnellan, 2012). Similarly, Robins et al. (2001) demonstrated high reliability of a single-item measure of self-esteem $\left(r_{x x}=.75\right)$ by applying a procedure introduced by Heise (1969). In this approach, the 
reliability of a single-item measure is estimated based on its pattern of autocorrelation across three measurement points. In the present study, we will adopt this approach to estimate the reliability of three single-item measures of loneliness.

\section{Direct and Indirect Measures of Loneliness}

In direct measures of loneliness, the respondents are confronted with the target construct insofar as words such as "lonely" are contained in the questions (e.g., "I am lonely"; "How often have you felt very lonely?"). Indirect measures, by contrast, avoid such references to loneliness (D. Russell, 1982). One item from the UCLA-LS, for example, asks participants to indicate "How often do you feel left out?", and an item from the RTLS asks participants to rate to what extent they agree with the statement "I experience a general sense of emptiness" (indicative of emotional loneliness).

The reasoning for using indirect measures is to disguise the researchers' interest in loneliness, thereby avoiding the activation of negative stereotypes and socially desirable responding (D. Russell, 1982). Previous studies have shown that gender differences in the prevalence of loneliness can be observed when direct measures are used, with men reporting lower levels of loneliness on average than women (Borys \& Perlman, 1985). Those gender differences disappear or even reverse when indirect measures are used (Maes et al., 2019). It should be noted that direct measures of loneliness are often single items, which, necessarily, are unidimensional. By contrast, most multi-item measures are indirect measures of loneliness (for an exception, see Rubenstein \& Shaver, 1980), and some of them are multi-dimensional.

\section{Convergent Validity, Self-Informant Agreement, and Nomological Nets}

Previous studies comparing different measures of loneliness for adults usually included no more than two measures at once and primarily considered their association with demographic variables (Borys \& Perlman, 1985; Cacioppo et al., 2006; Hughes et al., 2004; Iecovich, 2013; Maes et al., 2017; Shiovitz-Ezra \& Ayalon, 2012; Victor et al., 2005; von Soest et al., 2020). Regarding aspects of validity, we extend prior research in the present study by (a) considering multiple measures, and their facets, of loneliness for adults, (b) investigating correlations among self-reports and the agreement 
between self- and informant-ratings on those measures, and (c) considering a broad range of demographic and psychological variables to investigate similarities and differences in the nomological nets of those measures.

While several studies have investigated psychometric properties of multiple loneliness measures for children and adolescents (Cole et al., 2021; Goossens \& Beyers, 2002; Maes et al., 2017), studies on loneliness measures for adults have only compared two measures at once (Borys \& Perlman, 1985; Cacioppo et al., 2006; Hughes et al., 2004; Iecovich, 2013; Shiovitz-Ezra \& Ayalon, 2012; Victor et al., 2005; von Soest et al., 2020), with a particular focus on the UCLA-LS. However, examining the convergent validity of multiple measures is important to ensure that all those measures capture inter-individual differences in the same construct (Cronbach \& Meehl, 1955).

The correlation between self- and informant-reports is an important aspect of construct validity (Connelly \& Ones, 2010; McCrae et al., 2004; Podsakoff et al., 2003). If an instrument merely captures noise instead of reliable inter-individual differences, then the correlation with informant-ratings would be low (McCrae, 2015; Podsakoff et al., 2003). Thus, self-informant agreement is indicative of the substance of the measured construct (McCrae et al., 2004). Using a 9-item version of the UCLA-LS, Luhmann et al. (2016) found self-informant agreements for partnered individuals of $r=.37, .43$, and .66 , when the informants were friends, parents, and partners, respectively. For individuals without a partner, the self-informant agreement with friends amounted to $r=.43$ and to $r=.56$ with parents. Using the 20-item UCLA-LS, Lee and Ko (2018) reported a correlation of $r=.55$ between self-ratings and an aggregated informant-rating of up to three friends in a study with 118 self-(aggregated) informant pairs. Finally, also using the 20-item UCLA-LS, Mearns et al. (2009) reported a correlation of $r=.44$ between self-ratings and ratings by a friend, roommate, or parent in a study with 74 self-informant pairs. Studies investigating the self-informant agreement in adult samples for other measures than the UCLA-LS are lacking to date.

The construct validity of the measures investigated in the present work are further examined using a comprehensive nomological net (Cronbach \& Meehl, 1955). 
Previous studies comparing the nomological nets of loneliness measures for adults (Borys \& Perlman, 1985; Cacioppo et al., 2006; Hughes et al., 2004; Iecovich, 2013; Shiovitz-Ezra \& Ayalon, 2012; Victor et al., 2005; von Soest et al., 2020) were mostly restricted to a few, mostly demographic aspects. In the present work, we investigated broad nomological nets of the selected loneliness measures including demographic aspects, personality characteristics, domain-specific and life satisfaction, and aspects of social networks. Large differences in the nomological nets across measures would indicate that researchers and practitioners need to choose their measures carefully to make sure that they measure the intended aspects.

\section{The Present Work}

In this article, we present a series of three studies. In Study 1, we investigated the validity (convergence, self-other agreement, and nomological nets) of six measures of loneliness in a sample of young adults. In Study 2, we examined the validity of four partly different measures of loneliness than those used in Study 1. Furthermore, data in Study 2 were collected as part of a larger project on partner relationships; accordingly, informants in Study 2 were romantic partners. In Study 3, we investigated the reliability of three single-item measures of loneliness by designing a short-term prospective study with three measurement occasions each two weeks apart. The single studies were not preregistered. Analysis scripts and data used in the analyses are accessible at https://osf.io/7gsfw/?view_only=7e21e28c104549d0a5d9613495322148.

\section{Study 1: Validity of Six Loneliness Measures}

\section{Method}

\section{Sample}

The study was conducted in May 2018 as a cross-sectional online study using the formr survey framework (Arslan et al., 2020). The study was announced on several university mailing lists and on dedicated websites for people interested in psychological studies. The study protocol was approved by the Institutional Review Board of the Friedrich Schiller University Jena (FSV 18/03). A total of 697 German-speaking individuals participated in the self-rating part of the study. Among those, $72.17 \%$ were 
female. The majority of the participants were students (73.39\%), 15.88\% of the participants were employed or self-employed, $2.43 \%$ were enrolled in non-academic education (e.g., vocational learning, traineeship), and $1 \%$ were fulfilling a civil service; $7.30 \%$ of the participants were unemployed, unable to work because of ill-health, or not working for other reasons (e.g., retired, parental leave). On average, participants were 26.06 years $(\mathrm{SD}=9.84, M d n$ : 23) old, ranging from 18 to 99 years. After completion of the survey, participants received personalized feedback on their personality and well-being and could sign up for a voucher lottery.

Very early in the survey, participants were asked to provide contact details of up to five individuals who could provide ratings of the targets' personality and well-being. Those contacts were then sent an e-mail and asked to fill in a brief questionnaire. In this way, we obtained 282 informant-ratings on 163 targets. On average, the informants were 28.25 years old $(\mathrm{SD}=13.58, M d n=22)$, ranging from 18 to 70 years. Among the informants, $52 \%$ were friends of the targets, $23 \%$ were kin (e.g., parents, siblings), $18 \%$ were the target's romantic partner, $3 \%$ were acquaintances, $3 \%$ were colleagues, and $1 \%$ indicated to be in another relationship with the target. Given the uneven distribution of types of informants, we aggregated the ratings of all informants in the analyses.

Informants were asked to indicate how well they knew the target using a scale ranging from 0 (not well) to 10 (very well). On average, informants stated to know the targets very well $(8.43, \mathrm{SD}=1.54, M d n=9)$. Upon completion of the survey, informants were offered the option to sign up for a voucher lottery. Informants were also invited to take part in the self-rating. In this way, it was possible that self-raters also served as informants for other targets. Furthermore, it is possible that some individuals provided informant-ratings for more than one person. The primary data used for the analysis are available at https://osf.io/7gsfw/?view_only=7e21e28c104549d0a5d9613495322148.

\section{Measures}

Details on internal consistency, sample items, response formats, descriptive statistics, and zero-order correlations are provided in Supplemental Tables S1 to S3. 
Loneliness. The loneliness measures were presented in the self- and the informant-rating parts of the study.

Rasch-Type Loneliness Scale (RTLS). We used the 11-item version of the RTLS (de Jong Gierveld \& Kamphuis, 1985) to assess global loneliness and the facets emotional and social loneliness. Internal consistency (coefficient $\omega$ ) was high for self-ratings $\left(\omega_{\text {Total }}=.89, \omega_{\text {Emotional }}=.80, \omega_{\text {Social }}=.87\right)$ and informant-ratings $\left(\omega_{\text {Total }}=.87, \omega_{\text {Emotional }}=.83, \omega_{\text {Social }}=.82\right)$. RTLS $_{\text {Emotional }}$ and RTLS Social $_{\text {were highly }}$ correlated in the self- $(r=.66, p<.001)$ and the informant-ratings $(r=.61, p<.001)$.

UCLA Loneliness Scale (UCLA-L $\left.\boldsymbol{S}_{20 I t e m s}\right)$. We used the German version of the 20-item UCLA-LS (Döring \& Bortz, 1993; D. Russell et al., 1980). Internal consistency was high for self- $(\omega=.94)$ and informant-ratings $(\omega=.93)$.

3-item version of the $\boldsymbol{U C L A}$ Loneliness Scale (UCLA-L $\left.\boldsymbol{S}_{3 I t e m s}\right)$. We employed a 3-item version of the UCLA-LS that has been developed for use in large panel studies (Hawkley et al., 2015; Luhmann \& Hawkley, 2016). Internal consistency was satisfactory in the self- $(\omega=.78)$ and the informant-ratings $(\omega=.80)$.

Direct single-item measure (SI Direct). As a direct single-item measure of loneliness, we asked the participants to what extent the statement "I feel lonely" applies to them.

Indirect single-item measure (SI Indirect). As indirect single-item measure of loneliness, we asked participants to indicate their agreement with the statement "I feel alone".

Direct single-item frequency measure (SI Direct frequency $_{\text {). Adapting }}$ the SI Direct, we also asked participants about the frequency of loneliness (i.e., "How often do you feel lonely?").

Correlates of loneliness. All correlates were assessed only in the self-rating part of the study. We examined correlates from the domains of (a) demography, (b) personality, (c) satisfaction, and (d) network characteristics.

Demographic variables. Participants were asked to indicate their age, gender, educational status, and whether they currently have a partner or not. 
Personality. The Big Five personality traits were assessed using a 15-item version of the Big Five Inventory (Hahn et al., 2012). Self-esteem was assessed using a three-item version adapted from the Rosenberg Self-Esteem Scale that has been used previously in a large panel study (Huinink et al., 2011). Depressiveness was measured using the 10-item State-Trait Depression Scale (Spaderna et al., 2002). The explicit affiliation motive was assessed using four items from the Unified Motive Scales (Schönbrodt \& Gerstenberg, 2012). We also assessed need satisfaction of the affiliation motive by two items from the Basic Need Satisfaction and Frustration Scale (Chen et al., 2015). A product interaction between both variables was calculated to create an index of frustration of the affliation motive. Social desirability was assessed using the 17-item Social Desirability Scale (Stöber, 2001). Shyness and sociability were assessed using the Shyness and Sociability Scales for adults (Asendorpf \& Wilpers, 1998).

Satisfaction. Participants were asked to indicate their overall satisfaction with (a) life, (b) education, (c) leisure, (d) friends and social contacts, (e) family, and (f) partner relationship. These items were taken from larger panel studies (Huinink et al., 2011; Siedler et al., 2008).

Network Characteristics. Using single-item measures, participants were asked to indicate the number of (a) close friends, (b) friends on Facebook, (c) persons with whom the participant would be ready to discuss personal or occupational problems (i.e. emotional support), (d) persons who could be contacted for practical help (e.g., when relocating; i.e., instrumental support), and (e) persons the participant would ask for advice. Furthermore, participants were asked to indicate the frequency of (f) contact with their closest friend(s) and (g) joint activities with their friends.

\section{Analytic Procedure}

Convergent validity, operationalized as the correlation between the six loneliness measures, was assessed separately for self- and informant-ratings. Furthermore, for each measure, we examined the correlation between self- and informant-ratings. Nomological nets of the loneliness measures were examined by calculating the correlations with the external variables (e.g., demography, personality). 
To investigate whether the selected loneliness measures differ in their associations with external variables we conducted pairwise model comparisons. In the first step of this approach, we entered all available measures and allowed unrestricted correlations between the loneliness measures and the external variables, resulting in a saturated model. In a next step, we constrained the correlation between two loneliness measures (e.g., RTLS Total $_{\text {and }}$ UCLA-LS ${ }_{20 \text { Items }}$ ) and a correlate (e.g., shyness) to be equal. We then compared the fit of this constrained model to the unconstrained model via a $\chi^{2}$-difference test with 1 degree of freedom. A significant decrease in model fit in this setup indicated that the two loneliness measures differed significantly in their association with the external variable. Due to the large number of pairwise comparisons, we only consider differences significant when the $p$-value of the $\chi^{2}$-difference test was lower than .001. To facilitate the interpretation of the findings, we computed the average absolute correlation $(|\bar{r}|)$ for each loneliness measure and each domain (i.e., demography, personality, satisfaction, network characteristics).

To estimate differences in the correlation patterns between self- and informant-ratings as well as between Study 1 and Study 2, we calculated mean absolute deviations between correlation matrices $(|\overline{\Delta r}|)$. To examine the similarity of correlation profiles, we calculated the double-entry Intraclass Correlation $\left(I C C_{D E}\right.$; McCrae, 2008). Specifically, $I C C_{D E}$ was calculated to examine the profile similarity of the correlations between self- and informant-ratings as well as the different loneliness measures and the external correlates within and between studies. Furthermore, $I C C_{D E}$ was calculated to compare correlation profiles between Study 1 and Study 2. In all analyses, all variables were treated as manifest variables. All syntax files used in the study are available at https://osf.io/7gsfw/?view_only=7e21e28c104549d0a5d9613495322148.

\section{Results and Discussion}

\section{Convergent validity}

The intercorrelation between the different measures of loneliness are displayed in Table 1 separately for the self- and aggregated informant-ratings. Overall, the correlations were high for self-ratings $(\bar{r}=.63)$ and informant-ratings $(\bar{r}=.66)$. 
Furthermore, the average difference between the two correlation matrices were small $(|\overline{\Delta r}|=.08)$. Finally, the profile similarity between the coefficients in the two matrices was high $\left(I C C_{D E}=.97\right)$.

Within the self-ratings, the correlations between RTLS $_{\text {social }}$ and the three single items were lower than other associations and varied between $r=.43$ and $r=.47$. The UCLA-LS 20 Items was more strongly correlated with the $\operatorname{RTLS}_{\text {Total }}(r=.87)$ than the $\mathrm{UCLA} \mathrm{LS}_{3 \text { Items }}(r=.73)$. Likewise, the UCLA-LS $\mathrm{U}_{20 \text { Items }}$ was more strongly correlated with the $\operatorname{RTLS}_{\text {Social }}(r=.82)$ than the UCLA-LS ${ }_{3 I t e m s}(r=.57)$. Among the

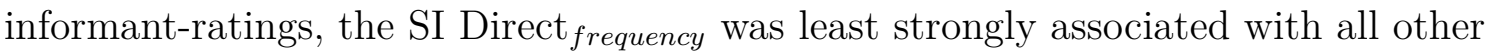
measures of loneliness $(.34 \leq r \leq .51)$.

Taken together, the findings converge with prior research showing high intercorrelations between different measures of loneliness for adults (Iecovich, 2013; D. Russell et al., 1980). Furthermore, we extended prior research by simultaneously examining the convergent validity of multi-item and single-item instruments, and by demonstrating that the high convergence between measures also extends to informant-ratings. Thus, we conclude that all the instruments included in Study 1 are appropriate to assess between-person differences in loneliness from an internal (i.e., self-ratings) as well as an external (i.e., informant-ratings) perspective.

\section{Self-informant agreement}

Table 2 displays the correlations between self- and aggregated informant-ratings. Self-informant agreement on the same scale (shown in the diagonal of Table 2) varied across instruments $(.49 \leq r \leq .61)$. The highest self-informant agreement was found for the $\operatorname{RTLS}_{\text {Total }}(r=.61)$ and the UCLA-LS 20 Items $(r=.61)$; the lowest agreement was observed for the SI Direct $(r=.49)$. Across all measures, the self-informant agreement amounted to $\bar{r}=.51$. This average correlation converges with other studies in which self-informant agreement in loneliness was investigated (Lee \& Ko, 2018; Luhmann et al., 2016; Mearns et al., 2009).

To our knowledge, this is the first study that investigated the self-informant agreement on multiple measures of loneliness. The results show that the overall 
convergence between self- and informant-ratings is high within and across measures. In fact, the amount of self-informant agreement found in the present and previous studies (Lee \& Ko, 2018; Luhmann et al., 2016; Mearns et al., 2009) is similar to self-informant agreement in broader personality characteristics such as the Big Five traits (for a meta-analysis, see Connelly \& Ones, 2010).

\section{The nomological nets of loneliness measures}

Table 3 displays the correlations between the different loneliness measures and a wide variety of correlates pertaining to demography, personality, satisfaction, and aspects of social networks. All correlations were compared pairwise via a model comparison with one degree of freedom. We will not go into detail on these model comparisons but instead highlight the overall pattern of results. To facilitate the interpretation, we computed scale-wise average absolute correlations $(|\bar{r}|)$ for each block of correlates (i.e., demography, personality, satisfaction, network characteristics). Table 4 shows scale-wise profile correlations derived from the correlations in Table 3.

Demography. All measures were only modestly related with demographic aspects. Average absolute correlations ranged from $|\bar{r}|=.06$ for the UCLA-LS IItems $_{\text {to }}$ $|\bar{r}|=.13$ for the UCLA-LS UItems and the RTLS Social $_{\text {. The UCLA-LS }}$ IItems was the only scale that was not significantly correlated with any of the demographic variables.

Personality. The correlations as displayed in Table 3 converged well with previous studies on loneliness and the Big Five (Buecker et al., 2020), self-esteem (Levin \& Stokes, 1986), and depression (Cacioppo et al., 2006). The average absolute correlations ranged from $|\bar{r}|=.20$ for the three single-item measures to $|\bar{r}|=.36$ for the UCLA-LS 20 Items. These differences held also when computing $|\bar{r}|$ for disattenuated correlations $\left(\operatorname{RTLS}_{\text {Total }}=.41, \operatorname{RTLS}_{\text {Emotional }}=.39, \operatorname{RTLS}_{\text {Social }}=.39\right.$,

$\mathrm{UCLA}_{20 \text { Items }}=.45, \mathrm{UCLA}_{3 \text { Items }}=.41$, SI Direct $=.29$, SI Indirect $=.27$, and SI

Direct $_{\text {frequency }}=.29$ - for the single-items, we used the reliability estimated in Study 3 as correction).

These differences were probably due to substantially lower correlations between the single items and personality aspects such as openness, agreeableness, 
conscientiousness, sociability, and need frustration. Furthermore, the correlations suggested that the UCLA-LS 20 Items was more strongly related to aspects associated with extraversion (i.e., sociability, shyness, affiliation motive) than other instruments.

Satisfaction with domains of life. The average absolute correlations between loneliness measures and domains of satisfaction ranged from $|\bar{r}|=.38$ for the SI Direct $_{\text {frequency }}$ to $|\bar{r}|=.47$ for the RTLS Total $_{\text {and the UCLA-LS }}$ aItems. The RTLS Rotal $_{\text {, }}$ $\mathrm{RTLS}_{\text {Emotional, }}$, and the UCLA-LS $\mathrm{U}_{20 \text { Items }}$ stood out in this regard with average absolute correlations between $|\bar{r}|=.45$ and $|\bar{r}|=.47$, whereas all other measures varied on a somewhat lower level with $.38 \leq|\bar{r}| \leq .40$. The largest differences between measures emerged for the association with satisfaction with friends and social contacts.

Single-item measures were less strongly associated with this aspect $(.43 \leq|\bar{r}| \leq .47)$, than the multi-item instruments $(.55 \leq|\bar{r}| \leq .66)$.

Network characteristics. Across all measures, loneliness was associated with smaller friendship and support networks. All measures were uncorrelated with the self-reported number of friends on Facebook. The average absolute correlations ranged from $|\bar{r}|=.13$ for the SI Direct ${ }_{\text {frequency }}$ to $|\bar{r}|=.31$ for the RTLS Social $_{\text {and the }}$ UCLA-LS ${ }_{20 I t e m s}$. Thus, as with the personality correlates, the UCLA-LS ${ }_{20 \text { Items }}$ seems to tap into aspects related to sociability and support. The average absolute correlations with network characteristics were particularly low for the single items $(|\bar{r}|=.13, .14, .16$

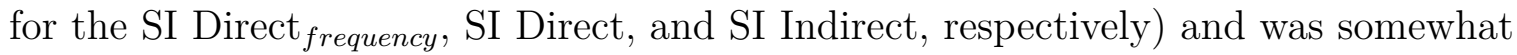
higher for the UCLA-LS $\mathrm{UItems}(|\bar{r}|=.20)$ and the $\mathrm{RTLS}_{\text {Emotional }}(|\bar{r}|=.22)$. Except for the number of friends providing instrumental support and advice, the single items were markedly less strongly correlated with network characteristics than the other instruments; these differences were particularly strong with regard to the frequency of contact with friends. In this case, the single items were not significantly correlated with this variable, whereas the multi-item scales were.

Profile similarity. The correlation between the profiles of the loneliness measures and the correlates examined in Study 1 are displayed in Table 4. On average, the profiles of the scales were very similar to each other, indicating that their 
nomological nets overlap to a large extent. Nevertheless, it might be noted that the profile correlation between the single items and the $\operatorname{RTLS}_{\text {Total }}\left(.87 \leq I C C_{D E} \leq .89\right)$, $\operatorname{RTLS}_{\text {Social }}\left(.82 \leq I C C_{D E} \leq .87\right)$, and UCLA-LS ${ }_{20 I t e m s}\left(.80 \leq I C C_{D E} \leq .84\right)$ were relatively low. By contrast, the profile correlations were substantially higher with the $\operatorname{RTLS}_{\text {Emotional }}\left(I C C_{D E}=.94\right)$ and the UCLA-LS UItems $\left(.92 \leq I C C_{D E} \leq .93\right)$. Likewise, the profile of the UCLA-LS 3 Items was less strongly correlated with the profile of the $\operatorname{RTLS}_{\text {Social }}\left(I C C_{D E}=.92\right)$ and the UCLA-LS ${ }_{20 I t e m s}\left(I C C_{D E}=.93\right)$ than with the $\mathrm{RTLS}_{\text {Emotional }}\left(I C C_{D E}=.98\right)$. By contrast, and resembling the findings presented in Table 3, the profile of the UCLA-LS 20 Items was closely related to the RTLS $\mathrm{S}_{\text {Social }}$ $\left(I C C_{D E}=.97\right)$.

\section{Summary and Conclusion}

Overall, the results of Study 1 show that (a) all measures of loneliness are highly correlated in the self- and the informant-reports, (b) self-informant agreement was high for all measures, and (c) all measures have a similar nomological net. These findings suggest that all measures tap into the same underlying latent construct and that there are no strong qualitative differences between the measures. It should be noted, though, that the nomological net of the single-item measures and - to a lesser extent - of the UCLA-LS 3 Items overlapped less strongly with related phenomena pertaining to personality (e.g., extraversion, sociability) and social networks (e.g., contact frequency). It could be argued that these measures provide purer assessments of loneliness. However, it could also be argued that these lower correlations are due to the lower reliability of these measures (Marangoni \& Ickes, 1989; D. Russell, 1982). Indeed, the UCLA-LS 3 Items had a lower internal consistency in the present study $(\omega=.78)$ than the $\operatorname{UCLA} \operatorname{LS}_{20 I t e m s}(\omega=.94)$ and the $\operatorname{RTLS}_{\text {Total }}(\omega=.89)$.

\section{Study 2: Validity of Four Loneliness Measures}

\section{Method}

\section{Sample}

The data used in Study 2 were taken from a larger online study on personality and partner relationships (Mund \& Drewke, 2020). The study protocol was approved by 
the Institutional Review Board of the Friedrich Schiller University Jena (FSV 18/47). The larger study combines features of longitudinal and diary methods in that couples are asked every three months about aspects of their own and their partner's personality, evaluations of the partner relationship, and aspects related to partner perception and communication patterns. In addition, participants are invited in February and March each year to participate in a diary period extending over 28 days in total, separated by a three-week break after the first 14 days. Participants were recruited via advertisements on social media platforms, several university mailing lists, and online forums visited by people interested in research participation (Mund \& Drewke, 2020).

In the present study, we use data from the first five longitudinal waves. These waves were conducted in January 2020, April 2020, July 2020, October 2020, and January 2021, respectively. We included data of couples when they participated for the first time. That is, for the purpose of the present study, we did not build on the longitudinal nature of the study, but on its dyadic nature and the large sample size. Accordingly, when a couple participated more than once, we only used data from the first time both partners provided data. This first-time participation could have been anytime during the five waves. In this way, we included data from 1,216 individuals (608 mixed-sex couples). Of those 608 couples, 136 entered the study in January 2020, 48 new couples entered in April 2020, 141 new couples entered in July 2020, 219 new couples entered in October 2020, and 64 new couples entered in January 2021.

Despite couples entering the study at different measurement occasions, Analyses of Variance indicated no mean level differences across waves for the UCLA-LS 8 Items $\left(F_{4,1208}=1.07, p=.37\right), \mathrm{UCLA}_{-L S}{ }_{3 \text { Items }}\left(F_{4,1207}=1.29, p=.27\right)$, or the SI Direct $\left(F_{3,753}=1.87, p=.13\right)$. There was a small difference, however, for the $\mathrm{RTLS}_{\text {Total }}$ $\left(F_{4,1193}=3.61, p=.006\right)$. Post-hoc Tukey tests revealed that the mean of the RTLS Total was significantly higher in October 2020 compared to April $2020(\Delta=0.26, p=.013)$. All other pairwise comparisons, however, were not statistically significant $(.075 \leq p \leq .999)$. This difference in the RTLS $_{\text {Total }}$ is attributable to differences between waves in the $\operatorname{RTLS}_{\text {Social }}\left(F_{4,1193}=3.37, p=.009\right)$. Tukey post-hoc tests 
indicated that social loneliness was higher in October 2020 than in January 2020 $(\Delta=0.18, p=.036)$ and April $2020(\Delta=0.27, p=.030)$. All other pairwise comparisons were not statistically significant $(.299 \leq p \leq .998)$. No difference between waves was observed for $\operatorname{RTLS}_{\text {Emotional }}\left(F_{4,1193}=2.19, p=.068\right)$. In sum, the few observed differences were small in size and inconsistent across loneliness measures. Accordingly, we decided to proceed with the analyses using this pooled data set.

On average, participants were 26.69 years old $(S D=4.86)$ and had been engaged in their current relationship for 40.85 months on average $(S D=40.91, M d n=28)$, with a range from two weeks to 44 years. The majority of couples lived in a non-institutionalized relationship (81.25\%), 11.35\% were married. The remaining participants indicated other relationship forms (e.g., in registered partnership) or preferred not to answer the question. A minority of participants $(5.83 \%)$ reported to have children. Of those, $81.25 \%$ reported to have one child, $11.35 \%$ reported to have two children, and $7.40 \%$ reported to have three or more children. As highest educational degree, $0.08 \%$ of participants reported to have finished primary school, $0.99 \%$ reported to have achieved a secondary school diploma, $6.71 \%$ have achieved a high school diploma, $6.13 \%$ have achieved an entrance qualification for a University of Applied Sciences (Fachabitur), 36.87\% have earned a University entrance qualification (Abitur), 47.97\% have earned a diploma from a University or a University of Applied Sciences, and 1.24\% have completed a $\mathrm{PhD}$. The remaining $0.01 \%$ of participants indicated "other" degrees or preferred not to answer this question. A subset of the data without any personal information (age, gender, etc.) is available from https://osf.io/7gsfw/?view_only=7e21e28c104549d0a5d9613495322148.

\section{Measures}

Details on internal consistency, sample items, response formats, descriptive statistics, and zero-order correlations are provided in Supplemental Tables S4 to S6.

Loneliness. For all loneliness measures, we obtained a self-rating and a partner-rating. That is, each participant rated and was rated by their partner on each loneliness measure. 
Rasch-Type Loneliness Scale (RTLS). In Study 2, we used the 6-item version of the RTLS (de Jong Gierveld \& van Tilburg, 2006), which also allows to differentiate between emotional and social loneliness. The correlation between the two facets was less strong than in Study 1 for both the self- $(r=.46, p<.001)$. and the partner-rating $(r=.47, p<.001)$. Internal consistency was high for the full scale and its facets in the self-rating $\left(\omega_{\text {Total }}=.78, \omega_{\text {Emotional }}=.68, \omega_{\text {Social }}=.83\right)$ as well as in the partner-rating $\left(\omega_{\text {Total }}=.79, \omega_{\text {Emotional }}=.66, \omega_{\text {Social }}=.85\right)$.

UCLA Loneliness Scale (UCLA-L $\boldsymbol{S}_{8 I t e m s}$ ). We used the German version of the 8-item UCLA-LS (Hays \& DiMatteo, 1987). Internal consistency was high for self- $(\omega=.80)$ and partner-ratings $(\omega=.81)$.

3-item version of the UCLA Loneliness Scale (UCLA-L $\left.S_{3 I t e m s}\right)$. As in Study 1, we employed a 3-item version of the UCLA-LS as proposed by Hawkley et al. (2015). Internal consistency was satisfactory in the self- $(\omega=.77)$ and the informant-ratings $(\omega=.81)$.

Direct single-item measure (SI Direct). As a direct single-item measure of loneliness, we used the same measure as employed in Study 1. Self-ratings of this item were collected in January 2020, April 2020, July 2020, and January 2021, but not in October 2020. The partner-ratings were collected at all measurement occasions.

Correlates of loneliness. As in Study 1, we used variables from several domains to examine the nomological net of the loneliness measures. Specifically, we used correlates from the domains of (a) demography, (b) personality, and (c) satisfaction.

Demographic variables. Participants were asked to indicate their age, gender, educational status, and their relationship duration.

Personality. The Big Five were assessed using a 15-item version of the Big Five Inventory Version 2 (Rammstedt et al., 2020; Soto \& John, 2017). Self-esteem was assessed using the 10-item Rosenberg Self-Esteem Scale (von Collani \& Herzberg, 2003). Depressiveness was measured using the five negatively-worded items from the State-Trait Depression Scale (Spaderna et al., 2002). The explicit affiliation motive was assessed using two items from the Unified Motive Scales (Schönbrodt \& Gerstenberg, 
2012). Shyness and sociability were assessed using the Shyness and Sociability Scales for adults (Asendorpf \& Wilpers, 1998). Sociability was only assessed at the first three measurement waves (January, April, July 2020, respectively).

Satisfaction. Participants were asked to indicate their overall satisfaction with (a) life, (b) education, (c) leisure, (d) friends and social contacts, and (e) family using single items (Huinink et al., 2011; Siedler et al., 2008). Relationship satisfaction was assessed with the 7-item Relationship Assessment Scale (Hendrick, 1988; Sander \& Böcker, 1993).

\section{Results and Discussion}

\section{Convergent validity}

The intercorrelation between the loneliness measures used in Study 2 are displayed in Table 5 separately for self- (below the diagonal) and partner-ratings (above the diagonal). For the self-ratings, intercorrelations were high $\bar{r}=.59$ and comparable to Study $1(\bar{r}=.63)$. The average correlation for the partner-ratings was lower $(\bar{r}=.47)$ than the average correlation in the self-ratings of Study 2 and the informant-ratings in Study $1(\bar{r}=.66)$. This relatively lower convergence seems to be due to the partner-rated SI Direct. For this item, the correlation with the other measures was weak, ranging from $r=.07$ with partner-rated RTLS $_{\text {Social }}$ to $r=.15$ with partner-ratings on the UCLA-LS ${ }_{8 \text { Items }}$. Without the SI Direct, the average correlation in the partner-ratings increased to $\bar{r}=.60$ - a value which is comparable to self-ratings in Study 2 and informant-ratings in Study 1.

The average difference between the self- and partner-ratings in Study 2 was $|\overline{\Delta r}|=.19$. Without the SI Direct, the two correlation matrices were nearly identical $(|\overline{\Delta r}|=.03)$. Similarly, the profile correlation between self- and partner-ratings amounted to $I C C_{D E}=.67$ for all measures and increased to $I C C_{D E}=.99$ when SI Direct was left out.

Finally, we compared the average differences and profile correlations between Study 1 and Study 2 separately for the self- and informant-ratings for the measures included in both studies (i.e., RTLS $_{11 \text { Items/6Items }}$ and facets, UCLA-LS 20 Items/8Items, 


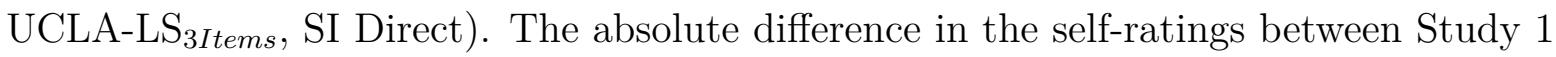
and Study 2 amounted to $|\overline{\Delta r}|=.16$. For the informant-ratings, $|\overline{\Delta r}|$ amounted to .31 when SI Direct was included and to .22 when SI Direct was left out. For both the selfand the informant-ratings, thus, the average differences in the intercorrelation were modest. With regard to the profile correlations between Study 1 and Study 2, $I C C_{D E}$ amounted to .86 for the self-ratings, indicating a very high similarity of the profiles across studies despite the fact that we used different measures in Study 2. For the informant-ratings, the profile similarity amounted to $I C C_{D E}=.65$ and was even higher $\left(I C C_{D E}=.83\right)$ when the SI Direct was excluded.

Taken together, the results regarding the convergent validity of different loneliness measures obtained in Study 2 converged very well with the results observed in Study 1. Across the two studies, the correlation profiles were very similar and the differences in the average correlations were small to moderate. Unlike Study 1, the SI Direct turned out to be somewhat problematic in the partner-rating of Study 2 in the sense that it showed only modest correlations with the other partner-rated loneliness measures. One possible explanation for this finding is that the SI Direct forced individuals to explicitly rate their partners as "lonely", which might threaten the self-concept of the rating partner. In Study 1, such effects might have been removed through the aggregation of the informant-ratings across multiple raters.

\section{Self-informant agreement}

The agreement between self- and partner-ratings are displayed in Table 6. The diagonal shows the agreement on the same instrument, ranging between $r=.22$ for the

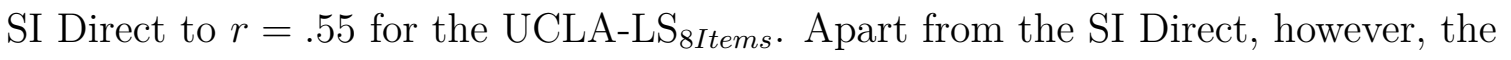
correlations in the diagonal are close to each other with $.42 \leq r \leq .55$. With the

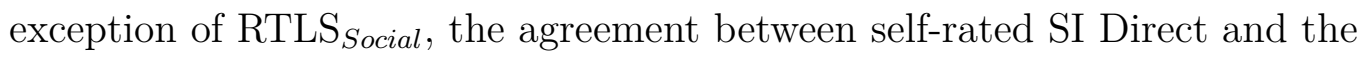
partner-rated measures are almost twice as high $(.42 \leq r \leq .44)$ as the correlation with partner-rated SI Direct $(r=.22)$. Across all measures, self-informant agreement amounted to $\bar{r}=.39$ with and to $\bar{r}=.43$ without the SI Direct, respectively. These coefficients were lower than the average correlation observed in Study $1(\bar{r}=.51)$. It 
should be noted, though, that we employed shorter measures of the UCLA-LS and the RTLS in Study 2 that evinced a weaker internal consistency. When correcting for attenuation, the self-informant agreement for the UCLA-LS ${ }_{8 I t e m s}$, for example, increased to $\hat{r}=.68$, which is very similar to a corrected self-informant agreement for the UCLA-LS ${ }_{20 I t e m s}$ in Study $1(\hat{r}=.65)$.

Comparing self-informant agreement between Study 1 and Study 2, we found a weak profile correlation of $I C C_{D E}=.16$. However, the average difference between the matrices is only small $(|\overline{\Delta r}|=.11)$. Thus, small shifts in the profiles might have led to the low profile similarity, whereas the actual coefficients do not differ much between Study 1 and Study 2.

\section{The nomological nets of loneliness measures}

The correlations between the different measures of loneliness and external correlates are displayed in Table 7. As in Study 1, we focus on the average absolute correlations $(|\bar{r}|)$ when discussing the results. Table 7 additionally contains the results of pairwise model tests with one degree of freedom for each scale and each correlate. The similarity between the correlation profiles of the different loneliness measures with external correlates is displayed in Table 8.

Demography. The absolute average correlations varied only slightly between the loneliness measures with $.04 \leq|\bar{r}| \leq .10$. In many cases, the correlations between the demographic aspects and the loneliness measures were not statistically significant.

Personality. Compared to Study 1, the absolute average correlations in Study 2 were substantially lower ranging from $|\bar{r}|=.22$ for $\operatorname{RTLS}_{\text {Social }}$ to $|\bar{r}|=.32$ for

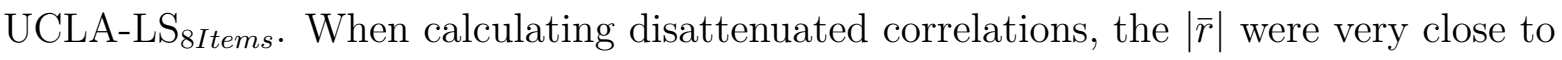
those observed in Study 1 RTLS $_{\text {Total }}=.39$ vs. .41, RTLS $_{\text {Emotional }}=.39$ vs. .39, $\mathrm{RTLS}_{\text {Social }}=.32$ vs. $.39, \mathrm{UCLA}_{8 \text { Items }}=.45$ vs. $.45, \mathrm{UCLA}_{3 \text { Items }}=.37$ vs. .41 , and SI Direct $=.37$ vs. .27), indicating that the lower correlations found in Study 2 might be attributed to the lower internal consistency of the abbreviated measures.

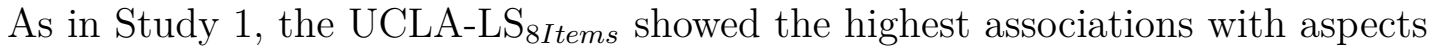
related to sociability (i.e., extraversion, sociability, shyness, affiliation) and, thus, was 


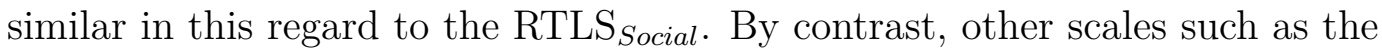
$\mathrm{UCLA}_{3 \text { Items }}$ or the SI Direct were less strongly or even not significantly associated with aspects of sociability.

Satisfaction. On average, there were no strong differences between the loneliness measures with $.27 \leq|\bar{r}| \leq .35$. The strongest differences between the measures emerged for satisfaction with friends and social contacts. In this domain, the

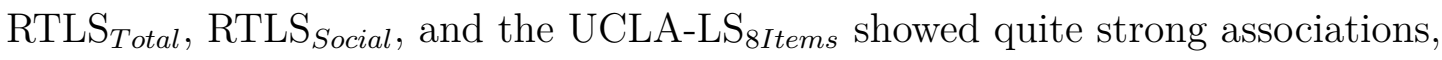
whereas the association with the remaining measures was lower.

Profile similarity between measures. The profile similarities for Study 2 are displayed in Table 8. The profiles of the different loneliness measures varied between $.77 \leq I C C_{D E} \leq .99$. The highest similarity was found between the SI Direct and the UCLA-LS ${ }_{3 I t e m s}$ and the lowest between RTLS $_{\text {Emotional }}$ and RTLS Social. Similarly, the profile correlations between RTLS $_{\text {Social }}$ and SI Direct (.84) and UCLA-LS IItems $_{\text {(.79) }}$ were lower than the profile similarities between other measures.

Comparing the profiles of the measures that were used in both studies (i.e.,

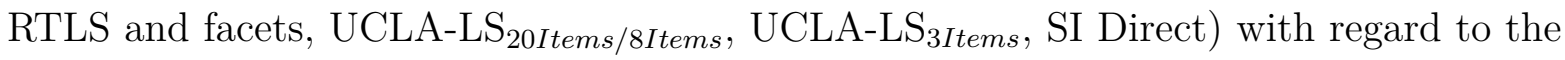
correlates that were used in both studies yielded a high profile similarity. Specifically, the profile similarity between the nomological nets in Study 1 and Study 2 was high for the $\operatorname{RTLS}_{\text {Total }}\left(I C C_{D E}=.92\right), \operatorname{RTLS}_{\text {Emotional }}\left(I C C_{D E}=.89\right), \operatorname{RTLS}_{\text {Social }}$ $\left(I C C_{D E}=.87\right), \mathrm{UCLA}_{\mathrm{LS}} \mathrm{LItems}_{\text {8Items }}\left(I C C_{D E}=.88\right), \mathrm{UCLA}_{\mathrm{LS}} \mathrm{LItems}\left(I C C_{D E}=.91\right)$, and SI Direct $\left(I C C_{D E}=.91\right)$. Thus, we conclude that the nomological nets of these popular measures are largely invariant across samples and studies.

\section{Summary and Conclusion}

The results of Study 2 compared well with the results obtained in Study 1. We found a similar pattern of convergent validity among different loneliness measures in the self-ratings and, with the exception of SI Direct, also in the partner-ratings of loneliness. Moreover, we found a very high similarity between the profiles of different loneliness measures and external correlates across the two studies. Although Study 2 cannot be considered a direct replication of Study 1, the similarity between the results 
indicates that the findings are robust. Thus, Study 2 further corroborates that all included measures are valid and reliable measures of loneliness in adults.

\section{Study 3: Reliability of Single-Item Measures}

In Studies 1 and 2, we found that the nomological nets of single-item measures of loneliness overlap less with phenomena related to extraversion and sociability. As mentioned in the previous discussions, this finding might either point to "purer" nomological nets or to a lack of validity of the single items - because of low reliability, their correlation with other constructs might be reduced.

Two previous studies have used STARTS models (Kenny \& Zautra, 2001) on single-item measures of loneliness (Mund, Lüdtke, et al., 2020; Zhong et al., 2016). In this way, Zhong et al. (2016) estimated a reliability of $r_{x x}=.595$ for a SI Direct, whereas the results reported by Mund, Lüdtke, et al. (2020) imply a reliability of different single item measures in the range between $.455 \leq r_{x x} \leq .524$. An alternative to STARTS models is a procedure proposed by Heise (1969). In this approach, the reliability of single-item measures is estimated based on their autocorrelations over three evenly spaced measurement occasions. In Study 3, we adopted this approach and examined the reliability of three single-item measures of loneliness.

\section{Method}

\section{Sample}

In 2019, we recruited a sample of 411 individuals via the service provider Prolific (www.prolific.com; for an overview, see Palan \& Schitter, 2018). As the study only involved self-rating, no ethical approval was necessary. On average, participants were 30.06 years old $(S D=9.23)$, ranging from 18 to $63(M d n=28)$. Almost half of the sample $(47.7 \%)$ were women. Regarding employment status, $46 \%$ and $25 \%$ of the sample reported to work full-time or part-time, respectively, $7.2 \%$ reported not to be in paid work (e.g., homemaker, disabled, retired). The remaining $\approx 12 \%$ of individuals reported to be currently job seeking, about to start a new job, or "other" status. Most participants were of German (76\%) or Austrian (14\%) nationality. The Prolific score (possible range from 0 to 100) of the participants, resembling the quality and validity of 
their responses based on previous studies they participated in, was high (mean $=99.57$, $S D=1.22, M d n=100$, range from 87 to 100$)$.

Two weeks after the first assessment (T1), all participants were reinvited to participate a second time (T2). Of the initial 411 individuals, 278 (67\%) participated again. Another two weeks later (i.e., 4 weeks after the initial assessment), all participants were invited to the third survey (T3) and 276 individuals (67\% compared to T1) provided the necessary data. For estimating the reliability of the single items, we conducted an analysis based on all available data and, separately, for the panel sample of 276 individuals who participated in all three assessment points. The data used for the key analyses are available from https://osf.io/7gsfw/?view_only=7e21e28c104549d0a5d9613495322148.

\section{Measures}

Loneliness. As measures of loneliness, we included the three single items also included in Study 1. That is, we included the SI Direct, SI Indirect, and the SI Direct $_{\text {frequency }}$.

Correlates. The three single-item measures of loneliness were interspersed with other measures. We included the three-item measure of self-esteem developed for large panel studies (Huinink et al., 2011) that was also used in the present Study 1. Furthermore, participants rated the frequency of being tense, joyful, sad, and happy. We will consider self-esteem in the following analyses, but the emotion ratings were merely used as fillers and will not be considered further.

\section{Analytic Strategy}

The procedure described by Heise (1969, Formula 9) requires three autocorrelations among the items measuring loneliness: The correlation between T1 and T2 $\left(r_{12}\right)$, T1 and T3 $\left(r_{13}\right)$, and T2 and T3 $\left(r_{23}\right)$. Based on these three correlations, reliability is estimated as $r_{x x}=\frac{r_{12} \times r_{23}}{r_{13}}$. We applied this formula separately to all three single-item measures. Moreover, we applied the formula to the point estimate of the observed correlations and additionally to the lower and upper bound of the $95 \%$ confidence interval of the observed correlations. 


\section{Results and Discussion}

Before estimating the reliability of the single-item measures, we investigated their correlation with the brief self-esteem measure. The correlation between self-esteem and SI Direct $\left(r_{T 1}=-.55, r_{T 2}=-.51, r_{T 3}=-.51\right)$, SI Indirect

$\left(r_{T 1}=-.53, r_{T 2}=-.53, r_{T 3}=-.45\right)$, and SI Direct ${ }_{\text {frequency }}$

$\left(r_{T 1}=-.51, r_{T 2}=-.52, r_{T 3}=-.45\right)$ converged well with the coefficients observed in the present Studies 1 and 2 and in previous studies (Levin \& Stokes, 1986).

Table 9 displays the reliability of the single-item measures of loneliness for the full and the panel sample. The highest reliability was estimated for the SI Indirect,

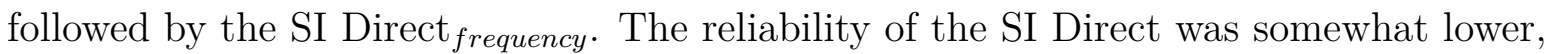
but still above typically used cut-offs of .70. Thus, these three single-item measures have a reliability that can at least be considered adequate. The often-cited notion that single items are unreliable appears questionable against the backdrop of the results of this analysis. Furthermore, the reliability estimated in the current study is similar to reliability estimates for single-items of self-esteem $\left(r_{x x}=.75\right.$ using the Heise approach; Robins et al., 2001) and life satisfaction (average $r_{x x}$ across four independent studies $=$ .72 using bivariate STARTS models; Lucas \& Donnellan, 2012). Thus, loneliness in adults can be reliably captured by single-item measures. This finding is particularly important when financial or time-related constraints do not allow researchers to include multi-item measures of loneliness.

\section{General Discussion}

In the present studies, we examined the psychometric features of several measures of loneliness - the perception of one's relationships as deficient regarding the quantitative and/or qualitative aspects (Ernst \& Cacioppo, 1999; Perlman \& Peplau, 1981). We included versions of the RTLS, UCLA-LS, and different single-item measures because those are among the most popular and widely-used measures of loneliness in adulthood (Buecker et al., 2020; Maes et al., 2019; Mund, Freuding, et al., 2020; Pinquart \& Sörensen, 2001). At the same time, these measures represent broader operationalizations of loneliness: The RTLS represents an indirect multidimensional 
approach, whereas the UCLA-LS represents an indirect unidimensional approach to loneliness. The included single-item measures are necessarily unidimensional, but represent both direct and indirect approaches. The present study largely extends previous research by (a) focusing on several loneliness measures at once, (b) using selfand informant-ratings to assess loneliness, (c) examining and comparing broad nomological nets, and (d) paying attention to the validity and reliability of different versions of single-item measures. The results presented in this article offer many vantage points for discussion, including (a) the similarities and differences between measures of loneliness, (b) the debate around the use of single items, and (c) recommendations for future research.

\section{Similarities and Differences Between Loneliness Measures}

In Study 1 and Study 2, we investigated the convergent validity of different measures of loneliness, self-informant agreement, and the nomological nets of these measures. The results indicate that all measures included in the present study are useful measures of loneliness. All measures show high convergent validity in the selfand informant-reports. Furthermore, the nomological nets of all measures were very similar to each other as indicated by high profile correlations. However, it should be noted that consistent across Study 1 and 2, the UCLA-LS, in its 20-item as well as in its 8-item version, was more strongly related to affiliative aspects like sociability and extraversion than the other measures, even after controlling for unreliability in the other instruments. Likewise, RTLS Social was more strongly related to sociability, extraversion (Studies 1 and 2), and network characteristics such as the frequency of joint activities

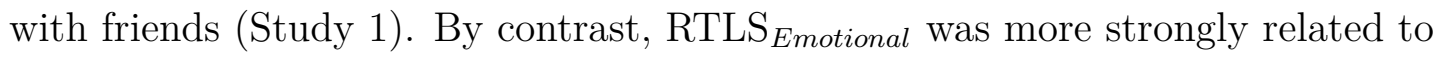
variables like neuroticism and self-esteem. Thus, the findings for the RTLS support the idea that, despite the high intercorrelation between its facets, it allows to differentiate between emotional and social aspects of loneliness (Green et al., 2001; van Baarsen et al., 2001). The correlation between the RTLS and UCLA-LS with personality and network characteristics demonstrates that the indirect approach taken by both instruments might come along with a less clear separation of loneliness from related 
constructs (Buecker et al., 2020). As we will discuss below, this approach might have consequences for specific research questions.

Consistent with prior research (Lee \& Ko, 2018; Luhmann et al., 2016; Mearns et al., 2009), self-informant agreement within and across measures was generally high and similar to self-informant agreement in broader personality characteristics (Connelly \& Ones, 2010). This finding indicates that loneliness is can be perceived by others. From a psychometric perspective, this supports the notion that the measures selected in the present article capture reliable inter-individual differences that are, to a large extent, validated by informants (McCrae et al., 2004; Podsakoff et al., 2003). From an applied perspective, this finding might also indicate that close others can accurately evaluate a person's loneliness. Thus, campaigns to tackle loneliness might also benefit from equipping close others with the knowledge of how to help and support lonely individuals in their environment in addition to encouraging lonely people to seek help proactively.

It should be noted that the informant-ratings in the present and previous studies (Lee \& Ko, 2018; Luhmann et al., 2016; Mearns et al., 2009) were obtained from close others such as partners, friends, or parents. Loneliness might be less well observable for less close informants, such as teachers or casual acquaintances (Geukens et al., 2021). Unlike extraversion, for example, which can be judged accurately even after a few seconds of interaction (Back \& Nestler, 2016; Connelly \& Ones, 2010; Vazire, 2010), loneliness is a rather internal state that might not manifest readily in specific observable behaviors (see also Vazire, 2010). Instead, loneliness might express itself in the content of interactions, for example by a specific emotional tone present in repeated conversations, or specific language patterns (Mehl et al., 2017; for findings on neuroticism, see Tackman et al., 2020) or interaction patterns (Tsai \& Reis, 2009).

\section{Debate Around Single-Item Measures}

The practice of measuring loneliness via single items has been controversial (Marangoni \& Ickes, 1989; D. Russell et al., 1980). However, single-item measures are highly prevalent in research on loneliness (Mund, Freuding, et al., 2020; Pinquart \& Sörensen, 2001) and frequently used in large-scale studies due to financial and 
time-related constraints.

In Study 1 and Study 2, we demonstrated that different versions of single-item measures correlate highly with each other and with multi-item scales. Furthermore, we demonstrated that the nomological nets of single items are consistent across different formulations and with the nomological nets of the established RTLS and UCLA-LS. In Study 3, we also demonstrated that single items are reliable measures. Thus, the results of the present studies indicate that single-item measures are not deficient or invalid measures of loneliness per se. Consequently, we argue that single-item measures of loneliness have their place as robust and trustworthy measures in research on loneliness (for a similar point regarding single-item measures of life satisfaction, see Cheung \& Lucas, 2014; Lucas \& Donnellan, 2012).

\section{Recommendations for Future Research}

Broadly speaking, when it comes to measuring the core of loneliness, we proclaim the well-known Dodo Verdict that "everybody has won, so all shall have prizes". Put differently, we believe that the phenomenon of loneliness in adulthood can be measured robustly, validly, and reliably by any of the measures investigated in this article.

A more nuanced view is necessary within specific research contexts. For example, in studies designed to investigate the behavioral correlates and/or the observability of loneliness, researchers need to take care that any observed effects are not due to other factors. For example, most studies that have examined self-informant agreement in loneliness have used the UCLA-LS (Lee \& Ko, 2018; Luhmann et al., 2016; Mearns et al., 2009). Given the results presented in the current studies, the high self-informant agreement found in these studies might be attributable, to some extent, to informants having actually observed the target's extraversion or sociability, which are well observable even for raters who are unacquainted with the target (Back \& Nestler, 2016; Connelly \& Ones, 2010). As another example, the similarity in loneliness between romantic partners has been found to be moderate $(r=.27)$ using the UCLA-LS IItems (Mund et al., in press), but to be near zero $(r=.08)$ in a study using a single item (Mund \& Johnson, 2021). By contrast, the effects of loneliness on later relationship 
satisfaction were similar in both studies.

The general recommendation that can be taken from the present findings is that loneliness measures should be selected with a particular regard to the research question. Some of the existing measures (e.g., RTLS, UCLA-LS) might need to be adjusted statistically to rule out confounding with overlapping constructs (e.g., extraversion). Furthermore, some measures might not work well when informant-ratings are to be collected, as was the case for the SI Direct in the present Study 2; in such cases, indirect measures might be better suited. Ideally, researchers should include multiple measures whenever possible to cross-check the results. The nomological nets presented in the current study might help to spot potential sources of disagreement between measures in existing and future research.

\section{Limitations}

The findings presented in this article should be evaluated against the backdrop of some limitations. First, recruitment of the participants was conducted via the Internet and, thus, was prone to self-selection. Overall, the samples were composed of mostly young and highly educated female adults. Hence, it is unclear whether the results can be generalized to samples from other age groups, other educational or cultural backgrounds, or with chronic health conditions.

Second, we investigated a selection of measurement instruments that are frequently used in contemporary research on loneliness in adulthood (Buecker et al., 2020; Maes et al., 2019; Mund, Freuding, et al., 2020; Pinquart \& Sörensen, 2001). However, other loneliness measures are also available. Some of those measures have been developed for samples of children or adolescents (Maes et al., 2015; Maes et al., 2017; Marcoen et al., 1987), and some have been developed with a broad multidimensional and relationship-specific perspective (DiTommaso \& Spinner, 1993; Hoza et al., 2000; Maes et al., 2015; Pollet et al., 2018). We hope that the nomological nets presented in the current study might serve as a foundation for further investigating the construct validity of those measures.

Third, although we investigated comprehensive nomological nets of the different 
loneliness measures, several important correlates were not considered. These include, first and foremost, health behaviors (Eccles et al., 2020; Shankar et al., 2011), but also other phenomena such as externalizing problems (e.g., hostility; Luhmann et al., 2015; Segel-Karpas \& Ayalon, 2020) or social media usage (Nowland et al., 2018).

Fourth, we used the included scales as intended by their original authors. That is, we used the RTLS as a multi-dimensional measure including the facets emotional and social loneliness (de Jong Gierveld \& Kamphuis, 1985; de Jong Gierveld \& van Tilburg, 2006) and the UCLA-LS as a unidimensional measure (D. Russell, 1982). Several studies have shown that the factor structure of these scales might be more complex (Grygiel et al., 2013; Hawkley et al., 2005; Iecovich, 2013; Maes et al., 2017). The question of the most appropriate factor structure of the included scales was beyond the scope of the present work, but would be a worthwhile endeavor for future research. For example, by a simultaneous factor analysis over multiple scales (Cramer \& Barry, 1999; Goossens \& Beyers, 2002; Maes et al., 2017), it might be possible to develop new scales reliably capturing the core of loneliness and its related facets.

\section{Conclusion}

Across three studies, we investigated aspects of the validity and reliability of different loneliness measures - including several versions of established scales such as the Rasch-Type Loneliness Scale and the University of California Los Angeles Loneliness Scale, but also different versions of single-item measures. Overall, the results indicate that all measures are highly correlated in self- as well as informant-ratings.

Furthermore, we found substantial self-informant agreement on all measures. The nomological nets of the included measures were shown to be consistent within and across studies. Finally, we have shown that single-item measures of loneliness possess adequate reliability. Taken together, the findings of the present studies provide rich evidence for the validity of popular loneliness measures, thereby providing a nuanced picture of each measure's nomological net. Thus, the present study might guide further research in selecting an appropriate loneliness measure and at the same time provides a solid foundation for future research on the validity of other loneliness measures. 


\section{References}

Arslan, R. C., Walther, M. P., \& Tata, C. S. (2020). Formr: A study framework allowing for automated feedback generation and complex longitudinal experience-sampling studies using R. Behavior Research Methods, 52(1), 376-387. https://doi.org/10.1207/S15374424jccp2901_12

Asendorpf, J. B., \& Wilpers, S. (1998). Personality effects on social relationships. Journal of Personality and Social Psychology, 74, 1531-1544. https://doi.org/10.1037/0022-3514.74.6.1531

Axelrod, R., \& Hamilton, W. D. (1981). The evolution of cooperation. Science, 211, $1390-1396$.

Back, M. D., \& Nestler, S. (2016). Accuracy of judging personality. In J. A. Hall, M. Schmid Mast, \& T. V. West (Eds.), The social psychology of perceiving others accurately (pp. 98-124). Cambridge University Press.

https://doi.org/10.1017/CBO9781316181959.005

Baumeister, R. F., \& Leary, M. R. (1995). The need to belong: Desire for interpersonal attachment as a fundamental human motivation. Psychological Bulletin, 117(3), 497-529. https://doi.org/10.1037/0033-2909.117.3.497

Beutel, M. E., Klein, E. M., Brähler, E., Reiner, I., Jünger, C., Michal, M., Wiltink, J., Wild, P. S., Münzel, T., Lackner, K. J., \& Tibubos, A. N. (2017). Loneliness in the general population: Prevalence, determinants and relations to mental health. BMC Psychiatry, 17, 97. https://doi.org/10.1186/s12888-017-1262-x

Borys, S., \& Perlman, D. (1985). Gender differences in loneliness. Personality and Social Psychology Bulletin, 11, 63-74. https://doi.org/10.1177/0146167285111006

Buecker, S., Maes, M., Denissen, J. J. A., \& Luhmann, M. (2020). Loneliness and the big five personality traits: A meta-analysis. European Journal of Personality, 34(1), 8-28. https://doi.org/10.1002/per.2229

Cacioppo, J. T., Cacioppo, S., Capitanio, J. P., \& Cole, S. W. (2015). The neuroendocrinology of social isolation. Annual Review of Psychology, 66, 733-767. https://doi.org/10.1146/annurev-psych-010814-015240 
Cacioppo, J. T., Chen, H. Y., \& Cacioppo, S. (2017). Reciprocal influences between loneliness and self-centeredness: A cross-lagged panel analysis in a population-based sample of African American, Hispanic, and Caucasian adults. Personality and Social Psychology Bulletin, 43(8), 1125-1135. https://doi.org/10.1177/014616721770512

Cacioppo, J. T., Hawkley, L. C., Ernst, J. M., Burleson, M., Berntson, G. G., Nouriani, B., \& Spiegel, D. (2006). Loneliness within a nomological net: An evolutionary perspective. Journal of Research in Personality, 40, 1054-1085. https://doi.org/10.1016/j.jrp.2005.11.007

Chen, B., Vansteenkiste, M., Beyers, W., Boone, L., Deci, E. L., van der Kaap-Deeder, J., Duriez, B., Lens, W., Matos, L., Mouratidis, A., Ryan, R. M., Sheldon, K. M., Soenens, B., van Petegem, S., \& Verstuyf, J. (2015). Basic psychological need satisfaction, need frustration, and need strength across four cultures. Motivation and Emotion, 39, 216-236. https://doi.org/10.1007/s11031-014-9450-1

Cheung, F., \& Lucas, R. E. (2014). Assessing the validity of single-item life satisfaction measures: Results from three large samples. Quality of Life Research, 23, 2809-2818. https://doi.org/10.1007/s11136-014-0726-4

Cohen, S. (2004). Social relationships and health. American Psychologist, 59, 676-684. https://doi.org/10.1037/0003-066X.59.8.676

Cole, A., Bond, C., Qualter, P., \& Maes, M. (2021). A systematic review of the development and psychometric properties of loneliness measures for children and adolescents. International Journal of Environmental Research and Public Health, 18(6), 3285. https://doi.org/10.3390/ijerph18063285

Connelly, B. S., \& Ones, D. S. (2010). An other perspective on personality: Meta-analytic integration of observers' accuracy and predictive validity. Psychological Bulletin, 136(6), 1092-1122. https://doi.org/10.1037/a0021212 
Cramer, K. M., \& Barry, J. E. (1999). Conceptualizations and measures of loneliness: A comparison of subscales. Personality and Individual Differences, 27, 491-502. https://doi.org/10.1016/S0191-8869(98)00257-8

Cronbach, L. J., \& Meehl, P. E. (1955). Construct validity in psychological tests. Psychological Bulletin, 52(4), 281-302. https://doi.org/10.1037/h0040957

de Jong Gierveld, J., \& Kamphuis, F. H. (1985). The development of a Rasch-type loneliness scale. Applied Psychological Measurement, 9, 289-299. https://doi.org/10.1177/014662168500900307

de Jong Gierveld, J., \& van Tilburg, T. (2006). A 6-item scale for overall, emotional, and social loneliness: Confirmatory tests on survey data. Research on Aging, 28, 582-598. https://doi.org/10.1177/0164027506289723

DiTommaso, E., \& Spinner, B. (1993). The development and initial validation of the social and emotional loneliness scale for adults (SELSA). Personality and Individual Differences, $14(1), 127-134$.

https://doi.org/10.1016/0191-8869(93)90182-3

Döring, N., \& Bortz, J. (1993). Psychometrische Einsamkeitsforschung: Deutsche Neukonstruktion der UCLA Loneliness Scale [Psychometric research on loneliness: German version of the UCLA loneliness scale]. Diagnostica, 39, 224-239.

Eccles, A. M., Qualter, P., Madsen, K. R., \& Holstein, B. E. (2020). Loneliness in the lives of Danish adolescents: Associations with health and sleep. Scandinavian Journal of Public Health, 48(8), 877-887.

https://doi.org/10.1177/1403494819865429

Ernst, J. M., \& Cacioppo, J. T. (1999). Lonely hearts: Psychological perspectives on loneliness. Applied and Preventive Psychology, 8, 1-22. https://doi.org/10.1016/S0962-1849(99)80008-0

Geukens, F., Maes, M., Cillessen, A. H. N., Colpin, H., van Leeuwen, K., Verschueren, K., \& Goossens, L. (2021). Spotting loneliness at school: Associations between self-reports and teacher and peer nominations. 
International Journal of Environmental Research and Public Health, $18(3), 971$. https://doi.org/10.3390/ijerph18030971

Goossens, L., \& Beyers, W. (2002). Comparing measures of childhood loneliness: Internal consistency and confirmatory factor analysis. Journal of Clinical Child 8 Adolescent Psychology, 31(2), 252-262. https://doi.org/10.1207/S15374424JCCP3102_10

Green, L. R., Richardson, D. S., Lago, T., \& Schatten-Jones, E. C. (2001). Network correlates of social and emotional loneliness in young and older adults. Personality and Social Psychology Bulletin, 27, 281-288. https://doi.org/10.1177/0146167201273002

Grygiel, P., Humenny, G., Rebisz, S., Świtaj, P., \& Sikorska, J. (2013). Validating the Polish adaptation of the 11-item de Jong Gierveld Loneliness Scale. European Journal of Psychological Assessment, 29, 129-139. https://doi.org/10.1027/1015-5759/a000130

Hahn, E., Gottschling, J., \& Spinath, F. M. (2012). Short measurement of personality: Validity and reliability of the GSOEP Big Five Inventory (BFI-S). Journal of Research in Personality, 46, 355-359. https://doi.org/10.1016/j.jrp.2012.03.008

Hartup, W. W., \& Stevens, N. (1997). Friendships and adaptation in the life course. Psychological Bulletin, 121, 355-370. https://doi.org/10.1037/0033-2909.121.3.355

Hawkley, L. C., Browne, M. W., \& Cacioppo, J. T. (2005). How can I connect with thee? Let me count the ways. Psychological Science, 16, 798-804.

Hawkley, L. C., \& Cacioppo, J. T. (2010). Loneliness matters: A theoretical and empirical review of consequences and mechanisms. Annals of Behavioral Medicine, 40, 218-227. https://doi.org/10.1007/s12160-010-9210-8

Hawkley, L. C., \& Capitanio, J. P. (2015). Perceived social isolation, evolutionary fitness and health outcomes: A lifespan approach. Philosophical Transactions of the Royal Society B, 370, 20140114. https://doi.org/10.1098/rstb_2014.0114 
Hawkley, L. C., Duvoisin, R., Ackva, J., Murdoch, J. C., \& Luhmann, M. (2015). Loneliness in older adults in the USA and Germany: Measurement invariance and validation. Working Paper Series, NORC at the University of Chicago, Paper 2015-002.

Hays, R. D., \& DiMatteo, M. R. (1987). A short-form measure of loneliness. Journal of Personality Assessment, 51(1), 69-81. https://doi.org/10.1207/s15327752jpa5101_6

Heinrich, L. M., \& Gullone, E. (2006). The clinical significance of loneliness: A literature review. Clinical Psychology Review, 26, 695-718. https://doi.org/10.1016/j.cpr.2006.04.002

Heise, D. R. (1969). Separating reliability and stability in test-retest correlation. American Sociological Review, 34, 93-101. http://www.jstor.org/stable/2092790

Hendrick, S. S. (1988). A generic measure of relationship satisfaction. Journal of Marriage and Family, 50, 93-98. https://doi.org/10.2307/352430

Holt-Lunstad, J., Smith, T. B., Baker, M., Harris, T., \& Stephenson, D. (2015). Loneliness and social isolation as risk factors for mortality: A meta-analytic review. Perspectives on Psychological Science, 10, 227-237. https://doi.org/10.1177/1745691614568352

House, J. S., Landis, K. R., \& Umberson, D. (1988). Social relationships and health. Science, 241, 540-545. http://www.jstor.org/stable/1701736

Hoza, B., Bukowski, W. M., \& Beery, S. (2000). Assessing peer network and dyadic loneliness. Journal of Clinical Child Psychology, 29(1), 119-128. https://doi.org/10.1207/S15374424jccp2901_12

Hughes, M. E., Waite, L. J., Hawkley, L. C., \& Cacioppo, J. T. (2004). A short scale for measuring loneliness in large surveys: Results from two population-based studies. Research on Aging, 26, 655-672. https://doi.org/10.1177/0164027504268574

Huinink, J., Brüderl, J., Nauck, B., Walper, S., Castiglioni, L., \& Feldhaus, M. (2011). Panel analysis of intimate relationships and family dynamics (pairfam): Conceptual framework and design. Zeitschrift für Familienforschung, 23, 77-101. 
Iecovich, E. (2013). Psychometric properties of the Hebrew version of the de Jong Gierveld Loneliness Scale. Educational Gerontology, 39, 12-27. https://doi.org/10.1080/03601277.2012.660860

Kenny, D. A., \& Zautra, A. (2001). Trait-state models for longitudinal data. In L. M. Collins \& A. G. Sayer (Eds.), New methods for the analysis of change (pp. 243-263). American Psychological Association.

Lee, Y., \& Ko, Y.-g. (2018). Feeling lonely when not socially isolated: Social isolation moderates the association between loneliness and daily social interaction. Journal of Social and Personal Relationships, 35(10), 1340-1355. https://doi.org/10.1177/0265407517712902

Levin, I., \& Stokes, J. P. (1986). An examination of the relation of individual difference variables to loneliness. Journal of Personality, 54(4), 717-733. https://doi.org/10.1111/j.1467-6494.1986.tb00422.x

Lodder, G. M. A., Scholte, R. H. J., Goossens, L., \& Verhagen, M. (2017). Loneliness in early adolescence: Friendship quantity, friendship quality, and dyadic processes. Journal of Clinical Child ES Adolescent Psychology, 46, 709-720. https://doi.org/10.1080/15374416.2015.1070352

Lucas, R. E., \& Donnellan, M. B. (2012). Estimating the reliability of single-item life satisfaction measures: Results from four national panel studies. Social Indicators Research, 105, 323-331. https://doi.org/10.1007/s11205-011-9783-z

Luhmann, M., Bohn, J., Holtmann, J., Koch, T., \& Eid, M. (2016). I'm lonely, can’t you tell? Convergent validity of self- and informant ratings of loneliness. Journal of Research in Personality, 61, 50-60. https://doi.org/10.1016/j.jrp.2016.02.002

Luhmann, M., \& Hawkley, L. C. (2016). Age differences in loneliness from late adolescence to oldest old age. Developmental Psychology, 52(6), 943-959. https://doi.org/10.1037/dev0000117

Luhmann, M., Schönbrodt, F. D., Hawkley, L. C., \& Cacioppo, J. T. (2015). Loneliness and social behaviours in a virtual social environment. Cognition and Emotion, $29(3)$, 548-558. https://doi.org/10.1080/02699931.2014.922053 
Maes, M., Klimstra, T., van den Noortgate, W., \& Goossens, L. (2015). Factor structure and measurement invariance of a multidimensional loneliness scale: Comparisons across gender and age. Journal of Child and Family Studies, 24, 1829-1837. https://doi.org/10.1007/s10826-014-9986-4

Maes, M., Qualter, P., Vanhalst, J., van den Noortgate, W., \& Goossens, L. (2019). Gender differences in loneliness across the lifespan: A meta-analysis. European Journal of Personality, 33, 642-654. https://doi.org/10.1002/per.2220

Maes, M., Vanhalst, J., van den Noortgate, W., \& Goossens, L. (2017). Intimate and relational loneliness in adolescence. Journal of Child and Family Studies, 26, 2059-2069. https://doi.org/10.1007/s10826-017-0722-8

Marangoni, C., \& Ickes, W. (1989). Loneliness: A theoretical review with implications for measurement. Journal of Social and Personal Relationships, 6, 93-128. https://doi.org/10.1177/026540758900600107

Marcoen, A., Goossens, L., \& Caes, P. (1987). Loneliness in pre- through late adolescence: Exploring the contribution of a multidimensional approach. Journal of Youth and Adolescence, 16, 561-577. https://doi.org/10.1007/BF02138821

McCrae, R. R. (2008). A note on some measures of profile agreement. Journal of Personality Assessment, $90(2)$, 105-109. https://doi.org/10.1080/00223890701845104

McCrae, R. R. (2015). A more nuanced view of reliability: Specificity in the trait hierarchy. Personality and Social Psychology Review, 19, 97-112. https://doi.org/10.1177/1088868314541857

McCrae, R. R., Costa, P. T., Martin, T. A., Oryol, V. E., Rukavishnikov, A. A., Senin, I. G., Hřebíčková, M., \& Urbánek, T. (2004). Consensual validation of personality traits across cultures. Journal of Research in Personality, 38(2), 179-201. https://doi.org/10.1016/S0092-6566(03)00056-4

Mearns, J., Patchett, E., \& Catanzaro, S. J. (2009). Multitrait-multimethod matrix validation of the Negative Mood Regulation Scale. Journal of Research in Personality, 43, 910-913. https://doi.org/10.1016/j.jrp.2009.05.003 
Mehl, M. R., Raison, C. L., Pace, T. W. W., Arevalo, J. M. G., \& Cole, S. W. (2017). Natural language indicators of differential gene regulation in the human immune system. PNAS, 114(47), 12554-12559. https://doi.org/10.1073/pnas.1707373114

Mund, M., \& Drewke, P. M. (2020). Loneliness in partner relationships: A dyadic examination of short- and long-term dynamics. OSF Preregistration. https://doi.org/10.17605/OSF.IO/NKCJ7

Mund, M., Freuding, M. M., Möbius, K., Horn, N., \& Neyer, F. J. (2020). The stability and change of loneliness across the lifespan: A meta-analysis of longitudinal studies. Personality and Social Psychology Review, 24(1), 24-52. https://doi.org/10.1177/1088868319850738

Mund, M., \& Johnson, M. D. (2021). Lonely me, lonely you: Loneliness and the longitudinal course of relationship satisfaction. Journal of Happiness Studies, 22, 575-597. https://doi.org/10.1007/s10902-020-00241-9

Mund, M., Lüdtke, O., \& Neyer, F. J. (2020). Owner of a lonely heart: The stability of loneliness across the life span. Journal of Personality and Social Psychology, $119(2)$, 497-516. https://doi.org/10.1037/pspp0000262

Mund, M., \& Neyer, F. J. (2016). The winding paths of the lonesome cowboy: Evidence for mutual influences between personality, subjective health, and loneliness. Journal of Personality, 84, 646-657. https://doi.org/10.1111/jopy.12188

Mund, M., Weidmann, R., Wrzus, C., Johnson, M. D., Bühler, J. L., Burriss, R. P., Wünsche, J., \& Grob, A. (in press). Loneliness is associated with the subjective evaluation of but not daily dynamics in partner relationships. International Journal of Behavioral Development. https://doi.org/10.1177/0165025420951246

Nowland, R., Necka, E. A., \& Cacioppo, J. T. (2018). Loneliness and social internet use: Pathways to reconnection in a digital world? Perspectives on Psychological Science, 13(1), 70-87. https://doi.org/10.1177/1745691617713052

Palan, S., \& Schitter, C. (2018). Prolific.ac: A subject pool for online experiments. Journal of Behavioral and Experimental Finance, 17, 22-27. https://doi.org/10.1016/j.jbef.2017.12.004 
Perlman, D., \& Peplau, L. A. (1981). Toward a social psychology of loneliness. In N. Duck \& R. Gilmour (Eds.), Personal relationships in disorder (pp. 31-56). Academic Press.

Pinquart, M., \& Sörensen, S. (2001). Gender differences in self-concept and psychological well-being in old age: A meta-analysis. Journal of Gerontology: Psychological Sciences, 56B, P195-P213.

Podsakoff, P. M., MacKenzie, S. B., Lee, J.-Y., \& Podsakoff, N. P. (2003). Common method biases in behavioral research: A critical review of the literature and recommended remedies. Journal of Applied Psychology, 88(5), 879-903. https://doi.org/10.1037/0021-9010.88.5.879

Pollet, T. V., Saxton, T. K., \& Mitchell, M. (2018). Measurement equivalence between men and women in the Abbreviated Social and Emotional Loneliness Scale for Adults (SELSA). Interpersona, 12(2), 283-292. https://doi.org/10.5964/ijpr.v12i2.316

Rammstedt, B., Danner, D., Soto, C. J., \& John, O. P. (2020). Validation of the short and extra-short forms of the Big Five Inventory-2 (BFI-2) and their German adaptations. European Journal of Psychological Assessment, 36(1), 149-161. https://doi.org/10.1027/1015-5759/a000481

Robins, R. W., Hendin, H. M., \& Trzesniewski, K. H. (2001). Measuring global self-esteem: Construct validation of a single-item measure and the Rosenberg Self-Esteem Scale. Personality and Social Psychology Bulletin, 27, 151-161. https://doi.org/10.1177/0146167201272002

Rubenstein, C. M., \& Shaver, P. (1980). Loneliness in two northeastern cities. In J. Hartog \& R. Audy (Eds.), The anatomy of loneliness (pp. 319-337). International University Press.

Russell, D., Peplau, L. A., \& Cutrona, C. E. (1980). The revised UCLA Loneliness Scale: Concurrent and discriminant validity evidence. Journal of Personality and Social Psychology, 39, 472-480. https://doi.org/10.1037/0022-3514.39.3.472 
Russell, D., Peplau, L. A., \& Ferguson, M. L. (1978). Developing a measure of loneliness. Journal of Personality Assessment, 42(3), 290-294. https://doi.org/10.1207/s15327752jpa4203_11

Russell, D. (1982). The measurement of loneliness. In L. A. Pervin \& D. Perlman (Eds.), Loneliness: A sourcebook of current theory, research and therapy (pp. 81-104). Wiliey.

Russell, D. W. (1996). UCLA loneliness scale (Version 3): Reliability, validity, and factor structure. Journal of Personality Assessment, 66, 20-40. https://doi.org/10.1207/s15327752jpa6601_2

Sander, J., \& Böcker, S. (1993). Die deutsche Form der Relationship Assessment Scale (RAS) [The German version of the Relationship Assessment Scale (RAS): A short scale for measuring satisfaction in a dyadic relationship]. Diagnostica, 39, $55-62$.

Schönbrodt, F. D., \& Gerstenberg, F. X. R. (2012). An IRT analysis of motive questionnaires: The Unified Motive Scales. Journal of Research in Personality, 46 (6), 725-742. https://doi.org/10.1016/j.jrp.2012.08.010

Segel-Karpas, D., \& Ayalon, L. (2020). Loneliness and hostility in older adults: A cross-lagged model. Psychology and Aging, 35(2), 169-176. https://doi.org/10.1037/pag0000417

Shankar, A., McMunn, A., Banks, J., \& Steptoe, A. (2011). Loneliness, social isolation, and behavioral and biological health indicators in older adults. Health Psychology, 30, 377-385. https://doi.org/10.1037/a0022826

Shiovitz-Ezra, S., \& Ayalon, L. (2010). Situational versus chronic loneliness as risk factors for all-cause mortality. International Psychogeriatrics, 22, 455-462. https://doi.org/10.1017/S1041610209991426

Shiovitz-Ezra, S., \& Ayalon, L. (2012). Use of direct versus indirect approaches to measure loneliness in later life. Research on Aging, 34, 572-591. https://doi.org/10.1177/0164027511423258 
Siedler, T., Schupp, J., Spiess, K. C., \& Wagner, G. G. (2008). The German Socio-Economic Panel as reference data set. RatSWD Working Paper, 48. https://doi.org/10.2139/ssrn.1445341

Soto, C. J., \& John, O. P. (2017). Short and extra-short forms of the Big Five Inventory-2: The BFI-2-S and BFI-2-XS. Journal of Research in Personality, 68, 69-81. https://doi.org/10.1016/j.jrp.2017.02.004

Spaderna, H., Schmukle, S. C., \& Krohne, H. W. (2002). Bericht über die deutsche Adaption der State-Trait Depression Scales (STDS) [Report about the German adaptation of the State-Trait Depression Scale (STDS)]. Diagnostica, 48, 80-89. https://doi.org/10.1026//0012-1924.48.2.80

Spithoven, A. W. M., Bastin, M., Bijttebier, P., \& Goossens, L. (2018). Lonely adolescents and their best friend: An examination of loneliness and friendship quality in best friendship dyads. Journal of Child and Family Studies, 27, 3598-3605. https://doi.org/10.1007/s10826-018-1183-4

Stöber, J. (2001). The Social Desirability Scale-17 (SDS-17): Convergent validity, discriminant validity, and relationship with age. European Journal of Psychological Assessment, 17(3), 222-232. https://doi.org/10.1027//1015-5759.17.3.222.

Tackman, A. M., Baranski, E. N., Danvers, A. F., Sbarra, D. A., Raison, C. L., Moseley, S. A., Polsinelli, A. J., \& Mehl, M. R. (2020). "Personality in its natural habitat" revisited: A pooled, multi-sample examination of the relationships between the big five personality traits and daily behaviour and language use. European Journal of Personality, 34 (5), 753-776. https://doi.org/10.1002/per.2283

Tsai, F.-F., \& Reis, H. T. (2009). Perceptions by and of lonely people in social networks. Personal Relationships, 16(2), 221-238. https://doi.org/10.1111/j.1475-6811.2009.01220.x

van Baarsen, B., Snijders, T. A. B., Smit, J. H., \& van Duijn, M. A. J. (2001). Lonely but not alone: Emotional isolation and social isolation as two distinct dimensions 
of loneliness in older people. Educational and Psychological Measurement, 61, 119-135. https://doi.org/10.1177/00131640121971103

Vazire, S. (2010). Who knows what about a person? The Self-Other Knowledge Asymmetry (SOKA) Model. Journal of Personality and Social Psychology, 98(2), 281-300. https://doi.org/10.1037/a0017908

Victor, C. R., Grenade, L., \& Boldy, D. (2005). Measuring loneliness in later life: A comparison of differing measures. Reviews in Clinical Gerontology, 15, 63-70. https://doi.org/10.1017/S0959259805001723

von Collani, G., \& Herzberg, P. Y. (2003). Eine revidierte Fassung der deutschsprachigen Skala zum Selbstwertgefühl von Rosenberg [A revised version of the German adaptation of the Rosenberg Self-Esteem Scale]. Zeitschrift für Differentielle und Diagnostische Psychologie, 24(1), 3-7.

von Soest, T., Luhmann, M., Hansen, T., \& Gerstorf, D. (2020). Development of loneliness in midlife and old age: Its nature and correlates. Journal of Personality and Social Psychology, 118(2), 388-406. https://doi.org/10.1037/pspp0000219

Weiss, R. S. (1973). Loneliness: The experience of emotional and social isolation. MIT Press.

Zhong, B.-L., Chen, S.-L., Tu, X., \& Conwell, Y. (2016). Loneliness and cognitive function in older adults: Findings from the Chinese Longitudinal Healthy Longevity Survey. The Journals of Gerontology Series B: Psychological Sciences and Social Sciences, 72, 120-128. https://doi.org/10.1093/geronb/gbw037 
Table 1

Study 1: Convergent Validity of Loneliness in Self- and Informant-Rating

\begin{tabular}{|c|c|c|c|c|c|c|c|c|}
\hline \multirow[b]{2}{*}{ Scale } & \multicolumn{3}{|c|}{ Rasch-Type Loneliness Scale } & \multicolumn{2}{|c|}{ UCLA Loneliness Scale } & \multicolumn{3}{|c|}{ Single Items } \\
\hline & Total & Emotional & Social & 20 Items & 3 Items & direct & indirect & direct frequency \\
\hline $\operatorname{RTLS}_{\text {Total }}$ & & .95 & .89 & .85 & .76 & .67 & .68 & .43 \\
\hline RTLS $_{\text {Emotional }}$ & .93 & & .72 & .80 & .75 & .72 & .70 & .44 \\
\hline $\operatorname{RTLS}_{\text {Social }}$ & .89 & .66 & & .77 & .65 & .49 & .53 & .34 \\
\hline UCLA-LS 20 Items & .87 & .77 & .82 & & .70 & .58 & .64 & .41 \\
\hline UCLA-LS 3 Items & .73 & .75 & .57 & .73 & & .61 & .65 & .39 \\
\hline SI Direct & .61 & .66 & .43 & .57 & .59 & & .74 & .48 \\
\hline SI Indirect & .62 & .64 & .47 & .59 & .56 & .70 & & .51 \\
\hline SI Direct frequency $_{\text {f }}$ & .66 & .71 & .46 & .63 & .66 & .81 & .67 & \\
\hline
\end{tabular}

Note. Self-rating $(N=657-679)$ is below the diagonal, informant-rating $(N=160)$ above the diagonal. All correlations are statistically significant at $p<.001$. RTLS: Rasch-Type Loneliness Scale. UCLA-LS: University of Los Angeles California Loneliness Scale. SI: Single Item. 
Table 2

Study 1: Self-Informant Agreement of the Different Loneliness Measures

\begin{tabular}{|c|c|c|c|c|c|c|c|c|}
\hline & \multicolumn{3}{|c|}{ Rasch-Type Loneliness Scale } & \multicolumn{2}{|c|}{ UCLA Loneliness Scale } & \multicolumn{3}{|c|}{ Single Items } \\
\hline & I-Total & I-Emotional & I-Social & I-20 Items & I-3 Items & I-Direct & I-Indirect & I-Direct Frequency \\
\hline $\mathrm{S} \mathrm{RTLS}_{\text {Total }}$ & .61 & & & & & & & \\
\hline S-RTLS $_{\text {Emotional }}$ & .56 & .57 & & & & & & \\
\hline S-RTLS $_{\text {Social }}$ & .58 & .56 & .52 & & & & & \\
\hline S-UCLA-LS 20 Items & .59 & .57 & .51 & .61 & & & & \\
\hline S-UCLA-LS 3 Items & .48 & .47 & .41 & .44 & .57 & & & \\
\hline S-SI Direct & .46 & .47 & .36 & .39 & .43 & .49 & & \\
\hline S-SI Indirect & .51 & .52 & .39 & .42 & .50 & .51 & .55 & \\
\hline S-SI Direct $_{\text {Frequency }}$ & .43 & .44 & .34 & .41 & .39 & .48 & .51 & .53 \\
\hline
\end{tabular}

Note. $\mathrm{N}=159-160$ pairs between self- and aggregated informant-ratings. S: Self-Rating; I: Informant-Rating. All correlations are statistically significant at $p<.001$. RTLS: Rasch-Type Loneliness Scale. UCLA-LS: University of Los Angeles California Loneliness Scale. SI: Single Item. 
Table 3

Study 1: Nomological Net of Different Measures of Loneliness (Self-Reports)

\begin{tabular}{|c|c|c|c|c|c|c|c|c|}
\hline \multirow[b]{2}{*}{ Variable } & \multicolumn{3}{|c|}{ Rasch-Type Loneliness Scale ${ }^{a}$} & \multicolumn{2}{|c|}{ UCLA Loneliness Scale } & \multicolumn{3}{|c|}{ Single Items } \\
\hline & Total & Emotional & Social & 20 Items & 3 Items & direct & indirect & direct frequency \\
\hline \multicolumn{9}{|l|}{ Demography } \\
\hline Age & $.05_{a}$ & $-.03_{b, c}$ & $.13_{d}$ & $.08_{a, d}$ & $-.05_{b, c}$ & $-.09_{b, c}$ & $.00_{a, c, d}$ & $-.10_{b}$ \\
\hline Gender $^{c}$ & $-.10_{a, c}$ & $-.04 b$ & $-.15_{b, c}$ & $-.15_{c}$ & $-.03_{a, b}$ & $-.04 a, b, c$ & $-.10_{a, b, c}$ & $-.03_{a, b}$ \\
\hline Education & $-.12_{a}$ & $-.10_{b}$ & $-.11_{b}$ & $-.11_{a, b}$ & $-.06_{a, b}$ & $-.11_{a, b}$ & $-.10_{a, b}$ & $-.11_{a, b}$ \\
\hline Partnered & $-.19_{a, c}$ & $-.21_{b}$ & $-.13_{b, c}$ & $-.18_{a, b, c}$ & $-.10_{c}$ & $-.25_{a, b}$ & $-.24_{a, b}$ & $-.23_{a, b}$ \\
\hline Average Absolute Correlation ${ }^{b}$ & .11 & .10 & .13 & .13 & .06 & .12 & .11 & .12 \\
\hline \multicolumn{9}{|l|}{ Personality } \\
\hline Neuroticism & $.29_{a, c}$ & $.34_{b}$ & $.18_{c}$ & $.24_{c}$ & $.37_{a, b}$ & $.21_{c}$ & $.19_{c}$ & $.26_{b, c}$ \\
\hline Extraversion & $-.34_{a, d}$ & $-.30_{c, e}$ & $-.33_{c, e}$ & $-.46_{b}$ & $-.33_{a, e}$ & $-.19_{d, f}$ & $-.20_{c, f}$ & $-.20_{c, f}$ \\
\hline Openness & $-.15_{a, d}$ & $-.08_{b}$ & $-.20_{c, d}$ & $-.20_{d}$ & $-.11_{a, b, c, d}$ & $-.07_{a, b, c}$ & $-.0 \%_{b, c}$ & $-.03_{b}$ \\
\hline Agreeableness & $-.23_{a, e}$ & $-.17_{c, d}$ & $-.27_{d}$ & $-.29_{a, d}$ & $-.16_{c, d, e}$ & $-.10_{b, c}$ & $-.13_{c, e}$ & $-.08_{b, c}$ \\
\hline Conscientiousness & $-.21_{a}$ & $-.18_{b}$ & $-.21_{b}$ & $-.22_{a, b}$ & $-.17_{a, b}$ & $-.18_{a, b}$ & $-.15_{a, b}$ & $-.16_{a, b}$ \\
\hline Shyness & $.34_{a, d}$ & $.33_{b, c, e}$ & $.28_{c, f}$ & $.39_{a, b}$ & $.39_{a, b, c}$ & $.25_{d, e, f}$ & $.24_{d, f}$ & $.27_{d, f}$ \\
\hline Sociability & $-.30_{a}$ & $-.19_{c}$ & $-.37_{d}$ & $-.42_{d}$ & $-.20_{c}$ & $-.06_{b}$ & $-.13_{b, c}$ & $-.06_{b}$ \\
\hline Self-Esteem & $-.53_{a}$ & $-.53_{b}$ & $-.42_{c}$ & $-.49_{a, b}$ & $-.53_{a, b, c}$ & $-.47_{a, b, c}$ & $-.46_{a, c}$ & $-.50_{a, b, c}$ \\
\hline Affiliation Motive & $-.25_{a}$ & $-.11_{c}$ & $-.36_{d}$ & $-.40_{b, d}$ & $-.09_{c, e}$ & $-.04 c, e$ & $-.11_{c}$ & $.00_{e}$ \\
\hline Unsatisfied Needs & $.57_{a}$ & $.49_{c, d}$ & $.48_{d, e}$ & $.57_{a, c}$ & $.55_{a, c, d}$ & $.38_{b, e}$ & $.33_{b}$ & $.37_{b, e}$ \\
\hline
\end{tabular}


Table 3 (continued)

\begin{tabular}{|c|c|c|c|c|c|c|c|c|}
\hline \multirow[b]{2}{*}{ Variable } & \multicolumn{3}{|c|}{ Rasch-Type Loneliness Scale ${ }^{a}$} & \multicolumn{2}{|c|}{ UCLA Loneliness Scale } & \multicolumn{3}{|c|}{ Single Items } \\
\hline & Total & Emotional & Social & 20 Items & 3 Items & direct & indirect & direct frequency \\
\hline Frustrated Affiliation Motive & $-.06_{a}$ & $-.01_{b}$ & $-.10_{b}$ & $-.10_{a, b}$ & $-.01_{a, b}$ & $-.06_{a, b}$ & $-.07_{a, b}$ & $.00_{a, b}$ \\
\hline Depressiveness & $.62_{a}$ & $.61_{c, d}$ & $.52_{b, d}$ & $.64_{a, c}$ & $.58_{a, b, c, d}$ & $.49_{b}$ & $.48_{b, e}$ & $.56_{a, d, e}$ \\
\hline Social Desirability & $-.05 a$ & $-.05 b$ & $-.05_{b}$ & $-.04 a, b$ & $-.05_{a, b}$ & $-.03_{a, b}$ & $-.01_{a, b}$ & $-.02_{a, b}$ \\
\hline Average Absolute Correlation ${ }^{b}$ & .32 & .27 & .30 & .36 & .29 & .20 & .20 & .20 \\
\hline \multicolumn{9}{|l|}{ Satisfaction with Domains of Life } \\
\hline Life & $-.53_{a}$ & $-.51_{b}$ & $-.45_{b}$ & $-.53_{a, b}$ & $-.43_{a, b}$ & $-.49_{a, b}$ & $-.53_{a, b}$ & $-.49_{a, b}$ \\
\hline Education & $-.36_{a}$ & $-.34_{b}$ & $-.32_{b}$ & $-.36_{a, b}$ & $-.33_{a, b}$ & $-.32_{a, b}$ & $-.30_{a, b}$ & $-.33_{a, b}$ \\
\hline Leisure & $-.45_{a}$ & $-.41_{b}$ & $-.40_{b}$ & $-.48_{a, b}$ & $-.38_{a, b}$ & $-.38_{a, b}$ & $-.40_{a, b}$ & $-.35_{a, b}$ \\
\hline Friends & $-.66_{a}$ & $-.64_{c}$ & $-.55_{c, d}$ & $-.64_{a, c}$ & $-.60_{a, c, e}$ & $-.47_{b, d, e}$ & $-.47_{b, d, e}$ & $-.43_{b, d}$ \\
\hline Family & $-.42_{a}$ & $-.37_{b}$ & $-.41_{b}$ & $-.44_{a, b}$ & $-.37_{a, b}$ & $-.39_{a, b}$ & $-.35_{a, b}$ & $-.35_{a, b}$ \\
\hline Partner Relationship & $-.34_{a}$ & $-.36_{c}$ & $-.26_{c, d}$ & $-.32_{a, c, d}$ & $-.21_{b, d, e}$ & $-.33_{a, c, e}$ & $-.34_{a, c, e}$ & $-.30_{a, c, e}$ \\
\hline Average Absolute Correlation ${ }^{b}$ & .47 & .45 & .40 & .47 & .39 & .40 & .40 & .38 \\
\hline \multicolumn{9}{|l|}{ Network Characteristics } \\
\hline \multicolumn{9}{|l|}{ Number of Friends (Providing)... } \\
\hline Overall & $-.32_{a, d}$ & $-.25_{b, c, e}$ & $-.35_{c, e}$ & $-.36_{a, b, c}$ & $-.24_{b, c, d}$ & $-.16_{a, d, e}$ & $-.17_{a, d, e}$ & $-.16_{d, e}$ \\
\hline on Facebook & $-.04 a$ & $-.01_{b}$ & $-.0 \%_{b}$ & $-.08_{a, b}$ & $-.03_{a, b}$ & $-.05_{a, b}$ & $-.05_{a, b}$ & $-.03_{a, b}$ \\
\hline Help with Problems & $-.38_{a, d}$ & $-.29_{b}$ & $-.42_{c}$ & $-.37_{a, c}$ & $-.23_{b, d}$ & $-.19_{a, b, d}$ & $-.20_{a, b, d}$ & $-.17_{d}$ \\
\hline Instrumental Support & $-.37_{a}$ & $-.31_{b, c}$ & $-.36_{b}$ & $-.35_{a, b}$ & $-.27_{a, b}$ & $-.22_{a, c}$ & $-.26_{a, b}$ & $-.21_{a, c}$ \\
\hline Advice & $-.22_{a}$ & $-.18_{b}$ & $-.23_{b}$ & $-.24_{a, b}$ & $-.16_{a, b}$ & $-.17_{a, b}$ & $-.19_{a, b}$ & $-.19_{a, b}$ \\
\hline
\end{tabular}




\begin{tabular}{|c|c|c|c|c|c|c|c|c|}
\hline \multirow[b]{2}{*}{ Variable } & \multicolumn{3}{|c|}{ Rasch-Type Loneliness Scale ${ }^{a}$} & \multicolumn{2}{|c|}{ UCLA Loneliness Scale } & \multicolumn{3}{|c|}{ Single Items } \\
\hline & Total & Emotional & Social & 20 Items & 3 Items & direct & indirect & direct frequency \\
\hline \multicolumn{9}{|l|}{ Frequency of... } \\
\hline Contact & $-.22_{a, e}$ & $-.15_{b, d}$ & $-.27_{b, c}$ & $-.27_{a, c}$ & $-.13_{d, e}$ & $-.02_{e, f}$ & $-.08_{a, d, f}$ & $-.02_{b, e, f}$ \\
\hline Joint Activities & $-.41_{a, d}$ & $-.34_{c}$ & $-.42_{c}$ & $-.45_{a}$ & $-.31_{b, c, d}$ & $-.17_{b, d}$ & $-.15_{b}$ & $-.12_{b}$ \\
\hline Average Absolute Correlation ${ }^{b}$ & .28 & .22 & .31 & .31 & .20 & .14 & .16 & .13 \\
\hline
\end{tabular}

Note. ${ }^{a}$ Due to the high correlation between the total score on the RTLS and its subfacets emotional and social loneliness, we ran different batches of models. In one batch, we compared the correlations between the full RTLS and all other scales, in the second batch, we compared the correlations between the emotional and social loneliness facets with all other scales. Hence, we could not test whether correlations differ between the full RTLS and its subfacets. ${ }^{b}$ Average correlations were calculated based on the absolute $z$-transformed correlations. After averaging, $z$-scores were re-transformed to $r$. ${ }^{c}$ Gender was coded as $1=$ female and $0=$ male/other. Different subscripts indicate a significantly different $(p<.001)$ correlation as judged by the results of a $\chi^{2}$-difference test with 1 degree of freedom. Italicized correlations have a $p$-value $\geq .01$. 
Table 4

Study 1: Profile Correlations Between Different Loneliness Measures

\begin{tabular}{|c|c|c|c|c|c|c|c|}
\hline \multirow[b]{2}{*}{ Scale } & \multicolumn{3}{|c|}{ Rasch-Type Loneliness Scale } & \multicolumn{2}{|c|}{ UCLA Loneliness Scale } & \multicolumn{2}{|r|}{ Single Items } \\
\hline & Total & Emotional & Social & 20 Items & 3 Items & direct & direct frequency \\
\hline \multicolumn{8}{|l|}{$\operatorname{RTLS}_{\text {Total }}$} \\
\hline RTLS $_{\text {Emotional }}$ & .98 & & & & & & \\
\hline $\operatorname{RTLS}_{\text {Social }}$ & .97 & .93 & & & & & \\
\hline UCLA-LS 20 Items & .98 & .94 & .97 & & & & \\
\hline UCLA-LS ${ }_{3 \text { Items }}$ & .96 & .98 & .92 & .93 & & & \\
\hline SI Direct & .88 & .94 & .84 & .82 & .93 & & \\
\hline SI Indirect & .89 & .94 & .87 & .84 & .92 & .99 & \\
\hline SI Direct frequency & .87 & .94 & .82 & .80 & .93 & .99 & .98 \\
\hline
\end{tabular}

Note. Table shows the correlations of the profiles of different loneliness scales with regard to the correlates displayed in Table 3 . Profile correlations are based on $z$-scores and were calculated using the double-entry ICC. RTLS: Rasch-Type Loneliness Scale. UCLA-LS: University of Los Angeles California Loneliness Scale. SI: Single Item. 
Table 5

Study 2: Convergent Validity of Loneliness in Self- and Informant-Rating

\begin{tabular}{|c|c|c|c|c|c|c|}
\hline \multirow[b]{2}{*}{ Scale } & \multicolumn{3}{|c|}{ Rasch-Type Loneliness Scale } & \multicolumn{2}{|c|}{ UCLA Loneliness Scale } & \multirow[b]{2}{*}{ SI Direct } \\
\hline & Total & Emotional & Social & 8 Items & 3 Items & \\
\hline $\operatorname{RTLS}_{\text {Total }}$ & & .85 & .86 & .74 & .67 & .12 \\
\hline RTLS $_{\text {Emotional }}$ & .86 & & .47 & .61 & .69 & .13 \\
\hline $\operatorname{RTLS}_{\text {Social }}$ & .84 & .46 & & .65 & .45 & .07 \\
\hline UCLA-LS ${ }_{8 I t e m s}$ & .71 & .63 & .58 & & .74 & .15 \\
\hline UCLA-LS $_{3 \text { Items }}$ & .65 & .69 & .42 & .76 & & .12 \\
\hline SI Direct & .66 & .66 & .45 & .67 & .66 & \\
\hline
\end{tabular}

Note. Self-rating $(N=757-1,212)$ is below the diagonal, informant-rating $(N=1,181-1,196)$ above the diagonal. Italicized correlations have a $p$-value $\geq .001$. RTLS: Rasch-Type Loneliness Scale.

UCLA-LS: University of Los Angeles California Loneliness Scale. SI: Single Item. 


\section{Table 6}

Study 2: Self-Informant Agreement of the Different Loneliness Measures

\begin{tabular}{|c|c|c|c|c|c|c|}
\hline & \multicolumn{3}{|c|}{ Rasch-Type Loneliness Scale } & \multicolumn{2}{|c|}{ UCLA Loneliness Scale } & \multirow[b]{2}{*}{ I-SI Direct } \\
\hline & I-Total & I-Emotional & I-Social & I-8 Items & I-3 Items & \\
\hline S-RTLS $_{\text {Total }}$ & .53 & & & & & \\
\hline S-RTLS Emotional $_{\text {. }}$ & .47 & .49 & & & & \\
\hline S-RTLS $_{\text {Social }}$ & .43 & .32 & .42 & & & \\
\hline S-UCLA-LS ${ }_{8 I t e m s}$ & .48 & .42 & .41 & .55 & & \\
\hline S-UCLA-LS 3 Items & .43 & .45 & .30 & .45 & .48 & \\
\hline S-SI Direct & .42 & .44 & .26 & .42 & .44 & .22 \\
\hline
\end{tabular}

Note. $\mathrm{N}=742-1,196$ pairs self- and partner-ratings. S: Self-Rating; I: Informant-Rating. All correlations are statistically significant at $p<.001$. RTLS: Rasch-Type Loneliness Scale. UCLA-LS: University of Los Angeles California Loneliness Scale. SI: Single Item. 


\section{Table 7}

Study 2: Nomological Nets of Different Measures of Loneliness (Self-Reports)

\begin{tabular}{|c|c|c|c|c|c|c|}
\hline \multirow[b]{2}{*}{ Variable } & \multicolumn{3}{|c|}{ Rasch-Type Loneliness Scale ${ }^{a}$} & \multicolumn{2}{|c|}{ UCLA Loneliness Scale } & \multirow[b]{2}{*}{ SI Direct } \\
\hline & Total & Emotional & Social & 8 Items & 3 Items & \\
\hline \multicolumn{7}{|l|}{ Demography } \\
\hline Age & $-.07_{a}$ & $-.15_{b}$ & $.04 c$ & $-.07_{a, b, c}$ & $-.15_{a, b}$ & $-.07_{a, b, c}$ \\
\hline Gender $^{c}$ & $-.01_{a}$ & $.06_{c}$ & $-.09_{d}$ & $.05_{a, c}$ & $.17_{b}$ & $.12_{b, c}$ \\
\hline Education & $-.13_{a}$ & $-.10_{b}$ & $-.11_{b}$ & $-.01_{b}$ & $-.01_{b}$ & $-.04 a, b$ \\
\hline Relationship Duration & $-.06_{a}$ & $-.10_{b}$ & $.01_{b}$ & $-.01_{a, b}$ & $-.06_{a, b}$ & $-.03_{a, b}$ \\
\hline Average Absolute Correlation ${ }^{b}$ & .07 & .10 & .06 & .04 & .10 & .06 \\
\hline \multicolumn{7}{|l|}{ Personality } \\
\hline Neuroticism & $.46_{a, d}$ & $.54_{b}$ & $.22_{c}$ & $.41_{a}$ & $.53_{b, d}$ & $.49_{a, b}$ \\
\hline Extraversion & $-.17_{a}$ & $-.09_{c}$ & $-.20_{c, d}$ & $-.30_{b, d}$ & $-.17_{a, c}$ & $-.15_{a, c}$ \\
\hline Openness & $.05_{a}$ & $.10_{b}$ & $-.02_{b}$ & $.04 a, b$ & $.07_{a, b}$ & $.08_{a, b}$ \\
\hline Agreeableness & $-.22_{a, f}$ & $-.14_{c, e}$ & $-.24_{c, d}$ & $-.27_{a, d}$ & $-.09_{b, e}$ & $-.16_{b, c, f}$ \\
\hline Conscientiousness & $-.20_{a}$ & $-.19_{b}$ & $-.15_{b}$ & $-.15_{a, b}$ & $-.18_{a, b}$ & $-.15_{a, b}$ \\
\hline Shyness & $.23_{a}$ & $.23_{c}$ & $.16_{c}$ & $.36_{b}$ & $.28_{a, b, c}$ & $.23_{a, c}$ \\
\hline Sociability & $-.14_{a}$ & $-.01_{c}$ & $-.24_{b}$ & $-.30_{b}$ & $-.05_{a, c}$ & $-.08_{a, c}$ \\
\hline
\end{tabular}


Table 7 (continued)

\begin{tabular}{|c|c|c|c|c|c|c|}
\hline \multirow[b]{2}{*}{ Variable } & \multicolumn{3}{|c|}{ Rasch-Type Loneliness Scale ${ }^{a}$} & \multicolumn{2}{|c|}{ UCLA Loneliness Scale } & \multirow[b]{2}{*}{ SI Direct } \\
\hline & Total & Emotional & Social & 8 Items & 3 Items & \\
\hline Self-Esteem & $-.54_{a}$ & $-.55_{b}$ & $-.36_{c}$ & $-.48_{a, b}$ & $-.51_{a, b}$ & $-.52_{a, b}$ \\
\hline Affiliation Motive & $-.12_{a}$ & $.05_{c}$ & $-.26_{b}$ & $-.24_{b}$ & $.01_{c}$ & $-.05_{a, c}$ \\
\hline Depressiveness & $.56_{a}$ & $.60_{b}$ & $.33_{c}$ & $.55_{a, b}$ & $.58_{a, b}$ & $.58_{a, b}$ \\
\hline Average Absolute Correlation $^{b}$ & .28 & .27 & .22 & .32 & .26 & .26 \\
\hline \multicolumn{7}{|l|}{ Satisfaction with Domains of Life } \\
\hline Life & $-.39_{a}$ & $-.35_{b}$ & $-.30_{b}$ & $-.34_{a, b}$ & $-.27_{b}$ & $-.31_{a, b}$ \\
\hline Education & $-.31_{a}$ & $-.30_{b}$ & $-.21_{b}$ & $-.23_{a, b}$ & $-.23_{a, b}$ & $-.25_{a, b}$ \\
\hline Leisure & $-.32_{a}$ & $-.29_{b}$ & $-.25_{b}$ & $-.33_{a, b}$ & $-.29_{a, b}$ & $-.30_{a, b}$ \\
\hline Friends & $-.50_{a, c}$ & $-.39_{b, d}$ & $-.45_{b}$ & $-.48_{a, b}$ & $-.39_{c, d, e}$ & $-.42_{a, b, e}$ \\
\hline Family & $-.29_{a}$ & $-.25_{b}$ & $-.23_{b}$ & $-.23_{a, b}$ & $-.22_{a, b}$ & $-.24_{a, b}$ \\
\hline Partner Relationship & $-.28_{a}$ & $-.27_{b}$ & $-.21_{b}$ & $-.24_{a, b}$ & $-.23_{a, b}$ & $-.29_{a, b}$ \\
\hline Average Absolute Correlation ${ }^{b}$ & .35 & .31 & .28 & .31 & .27 & .30 \\
\hline
\end{tabular}


Table 7 (continued)

\begin{tabular}{|c|c|c|c|c|c|c|}
\hline \multirow[b]{2}{*}{ Variable } & \multicolumn{3}{|c|}{ Rasch-Type Loneliness Scale ${ }^{a}$} & \multicolumn{2}{|c|}{ UCLA Loneliness Scale } & \multirow[b]{2}{*}{ SI Direct } \\
\hline & Total & Emotional & Social & 8 Items & 3 Items & \\
\hline
\end{tabular}

Note. ${ }^{a}$ Due to the high correlation between the total score on the RTLS and its subfacets emotional and social loneliness, we ran different batches of models. In one batch, we compared the correlations between the full RTLS and all other scales, in the second batch, we compared the correlations between the emotional and social loneliness facets with all other scales. Hence, we could not test whether correlations differ between the full RTLS and its subfacets. ${ }^{b}$ Average correlations were calculated based on the absolute $z$-transformed correlations. After averaging, $z$-scores were re-transformed to $r$. ${ }^{c}$ Gender was coded as $1=$ female and $0=$ male/other. Different subscripts indicate a significantly different $(p<.001)$ correlation as judged by the results of a $\chi^{2}$-difference test with 1 degree of freedom. Italicized correlations have a $p$-value $\geq .01$. 
Table 8

Study 2: Profile Correlations Between Different Loneliness Measures

\begin{tabular}{|c|c|c|c|c|c|c|}
\hline \multirow[b]{2}{*}{ Scale } & \multicolumn{3}{|c|}{ Rasch-Type Loneliness Scale } & \multicolumn{2}{|c|}{ UCLA Loneliness Scale } & \multirow[b]{2}{*}{ SI Direct } \\
\hline & Total & Emotional & Social & 8 Items & 3 Items & \\
\hline \multicolumn{7}{|l|}{$\operatorname{RTLS}_{\text {Total }}$} \\
\hline RTLS $_{\text {Emotional }}$ & .97 & & & & & \\
\hline $\operatorname{RTLS}_{\text {Social }}$ & .88 & .77 & & & & \\
\hline $\mathrm{UCLA} \mathrm{LS}_{8 \text { Items }}$ & .96 & .91 & .90 & & & \\
\hline $\mathrm{UCLA} \mathrm{LS}_{3 \text { Items }}$ & .95 & .98 & .79 & .93 & & \\
\hline SI Direct & .98 & .98 & .84 & .95 & .99 & \\
\hline
\end{tabular}

Note. Table shows the correlations of the profiles of different loneliness scales with regard to the correlates displayed in Table 7. Profile correlations are based on $z$-scores and were calculated using the double-entry ICC. RTLS: Rasch-Type Loneliness Scale. UCLA-LS: University of Los Angeles California Loneliness Scale. SI: Single Item. 
Table 9

Study 3: Reliability of Single-Item Measures

\begin{tabular}{|c|c|c|c|c|c|c|c|c|c|}
\hline \multirow[b]{2}{*}{ Scale } & \multicolumn{3}{|c|}{ Full $(\mathrm{N}=411)$} & \multicolumn{3}{|c|}{ Panel $(\mathrm{N}=276)$} & \multicolumn{3}{|c|}{ Correlations at $\mathrm{T} 1^{a}$} \\
\hline & $r_{x x}$ & $\mathrm{LB}$ & UB & $r_{x x}$ & $\mathrm{LB}$ & UB & 1 & 2 & 3 \\
\hline 1 SI Direct & .71 & .65 & .76 & .74 & .66 & .77 & & .79 & .82 \\
\hline 2 SI Indirect & .82 & .77 & .85 & .85 & .81 & .88 & .80 & & .72 \\
\hline 3 SI Direct $_{\text {frequency }}$ & .77 & .71 & .81 & .80 & .74 & .84 & .81 & .74 & \\
\hline
\end{tabular}

Note. ${ }^{a}$ Correlations in the Full Sample are displayed below the diagonal, correlations in the Panel Sample are displayed above the diagonal. SI: Single Item. $r_{x x}$ : reliability as estimated by Formula 9 presented in Heise (1969). LB: lower bound of the $95 \%$ confidence interval of the estimated reliability. UB: upper bound of the $95 \%$ confidence interval of the estimated reliability. 
Supplemental Material

Would the Real Loneliness Please Stand Up? The

Validity of Loneliness Measures and the Reliability of Single Items 
Study 1 


\section{Table S1}

Overview of the Measures Used in Study 1

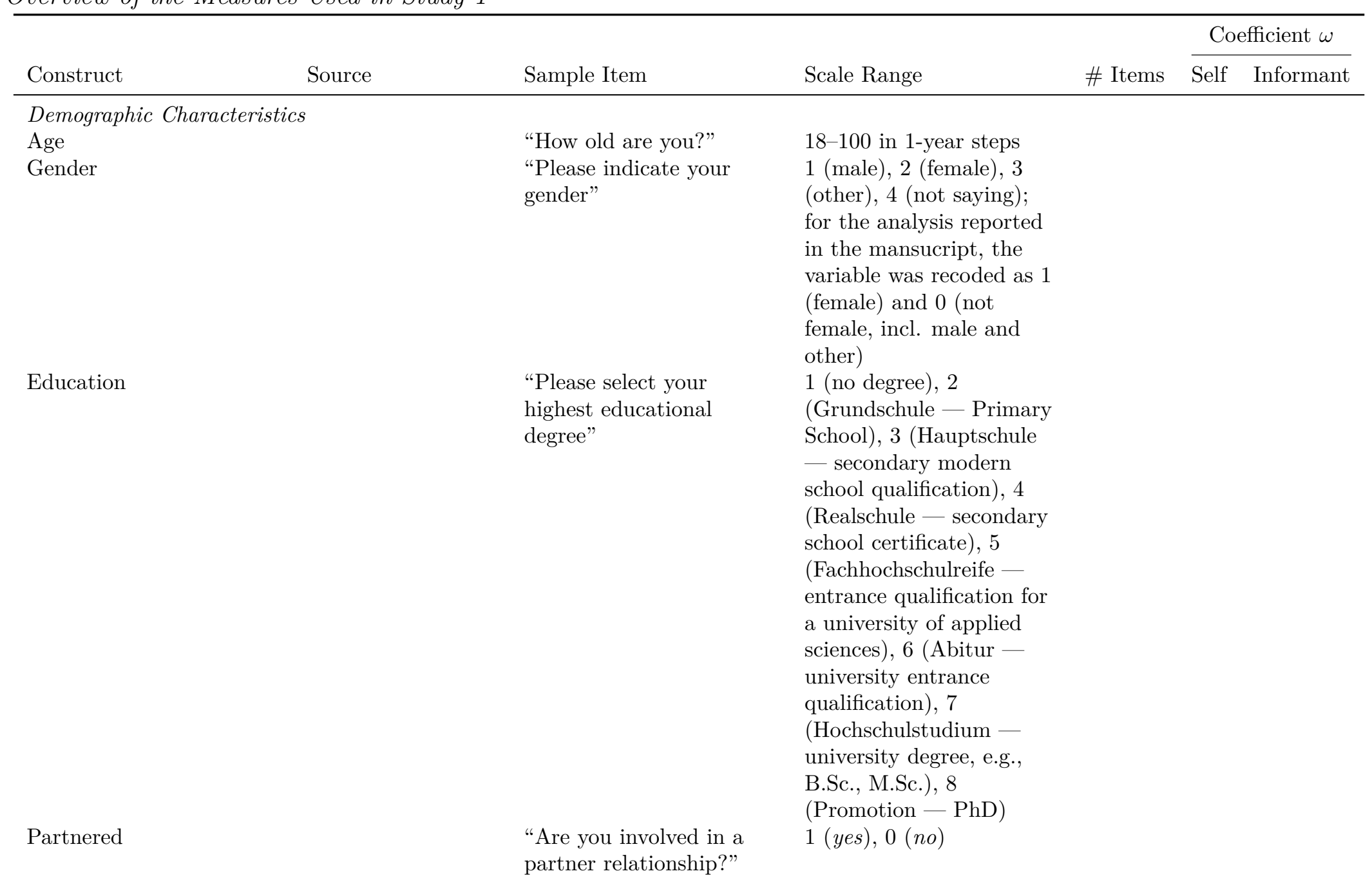


ect Single Item (SI

Direct)

Indirect Single Item (SI

Indirect)

Direct Single Item

Frequency (SI

Direct $_{\text {Frequency }}$ )

Personality

Neuroticism

Extraversion
Source

de Jong Gierveld

and Kamphuis

(1985)

de Jong Gierveld

and Kamphuis

(1985)

de Jong Gierveld

and Kamphuis

(1985)

Döring and Bortz

(1993)

Hawkley et al. (2015)

\section{Döring and Bortz} (1993)

1 (does not apply) to 5

(fully applies)

"I experience a general

sense of emptiness"

"There are plenty of

people I can rely on when

I have problems", reverse scored

"Nobody really knows me"

1 (does not apply) to 5 (fully applies)

1 (does not apply) to 5

(fully applies)

1 (completely false) to 5 (completely true

1 (never) to 5 (very

"How often do you have

the feeling to be left out";

"How often do you have

the feeling to be

isolated"; "How often do

you have the feeling to

lack companionship"

"I feel lonely"

1 (does not at all apply)

1

to 5 (does fully apply)

1 (does not at all apply) 1

to 5 (does fully apply)

"How often do you feel

1 (never) to 5 (always)

1

lonely"

Coefficient $\omega$

Items Self Informant

$\begin{array}{lll}11 & .89 & .87\end{array}$

6

80

$5 \quad .87$

20

1 (never) to 5 (always)

1

"I see myself as someone 1 (do not agree at all) to

3 who worries a lot"

7 (fully agree)

"I see myself as someone 1 (do not agree at all) to

3

Hahn et al. 2012

who is communicative"

7 (fully agree) 


\begin{tabular}{|c|c|c|c|c|c|c|}
\hline \multirow[b]{2}{*}{ Construct } & \multirow[b]{2}{*}{ Source } & \multirow[b]{2}{*}{ Sample Item } & \multirow[b]{2}{*}{ Scale Range } & \multirow[b]{2}{*}{ \# Items } & \multicolumn{2}{|c|}{ Coefficient $\omega$} \\
\hline & & & & & Self & Informant \\
\hline Openness & Hahn et al. (2012), & $\begin{array}{l}\text { "I see myself as someone } \\
\text { who is original" }\end{array}$ & $\begin{array}{l}1 \text { (do not agree at all) to } \\
7 \text { (fully agree) }\end{array}$ & 3 & .68 & \\
\hline Agreeableness & Hahn et al. (2012) & $\begin{array}{l}\text { "I see myself as someone } \\
\text { who has a forgiving } \\
\text { nature" }\end{array}$ & $\begin{array}{l}1 \text { (do not agree at all) to } \\
7 \text { (fully agree })\end{array}$ & 3 & .54 & \\
\hline Conscientiousness & Hahn et al. (2012) & $\begin{array}{l}\text { "I see myself as someone } \\
\text { who does things } \\
\text { effectively" }\end{array}$ & $\begin{array}{l}1 \text { (do not agree at all) to } \\
7 \text { (fully agree })\end{array}$ & 3 & .71 & \\
\hline Self-Esteem & $\begin{array}{l}\text { German Family } \\
\text { Panel }\end{array}$ & $\begin{array}{l}\text { "I like myself just the } \\
\text { way I am" }\end{array}$ & $\begin{array}{l}1 \text { (do not agree at all) to } \\
5 \text { (fully agree) }\end{array}$ & 3 & .80 & \\
\hline Depressiveness & $\begin{array}{l}\text { Spaderna et al. } \\
(2002)\end{array}$ & $\begin{array}{l}\text { "In general, how often do } \\
\text { you feel sad" }\end{array}$ & $\begin{array}{l}1 \text { (almost never) to } 4 \\
\text { (almost always) }\end{array}$ & 10 & .91 & \\
\hline Affiliation Motive & $\begin{array}{l}\text { Schönbrodt and } \\
\text { Gerstenberg }(2012)\end{array}$ & $\begin{array}{l}\text { "How important is it for } \\
\text { you to be in the company } \\
\text { of friends?" }\end{array}$ & $\begin{array}{l}1 \text { (not important) to } 6 \\
\text { (very important) }\end{array}$ & 4 & .73 & \\
\hline Need Satisfaction & Chen et al. (2015). & $\begin{array}{l}\text { "In general, people are } \\
\text { friendly with me", reverse } \\
\text { scored }\end{array}$ & $\begin{array}{l}1 \text { (does not apply) to } 5 \\
\text { (applies fully) }\end{array}$ & 2 & .66 & \\
\hline Social Desirability & Stöber (2001) & $\begin{array}{l}\text { "In traffic I am always } \\
\text { polite and considerate of } \\
\text { others" }\end{array}$ & true/false & 17 & .71 & \\
\hline Shyness & $\begin{array}{l}\text { Asendorpf and } \\
\text { Wilpers }(1998)\end{array}$ & $\begin{array}{l}\text { "I feel inhibited when I } \\
\text { am with other people" }\end{array}$ & $\begin{array}{l}1 \text { (does not apply) to } 5 \\
\text { (applies fully) }\end{array}$ & 5 & .76 & \\
\hline Sociability & $\begin{array}{l}\text { Asendorpf and } \\
\text { Wilpers (1998) }\end{array}$ & $\begin{array}{l}\text { "I really like to talk to } \\
\text { other people" }\end{array}$ & $\begin{array}{l}1 \text { (does not apply) to } 5 \\
\text { (applies fully) }\end{array}$ & 5 & .79 & \\
\hline \multicolumn{7}{|l|}{ Satisfaction } \\
\hline Life & Siedler et al. (2008) & $\begin{array}{l}\text { "In general, how satisfied } \\
\text { are you with your life" }\end{array}$ & $\begin{array}{l}0 \text { (very dissatisfied) to } 10 \\
\text { (very satisfied) }\end{array}$ & 1 & & \\
\hline Education & Siedler et al. (2008) & $\begin{array}{l}\text { "In general, how satisfied } \\
\text { are you with your } \\
\text { education and work life" }\end{array}$ & $\begin{array}{l}0 \text { (very dissatisfied) to } 10 \\
\text { (very satisfied) }\end{array}$ & 1 & & \\
\hline
\end{tabular}




\begin{tabular}{|c|c|c|c|c|c|c|}
\hline \multirow[b]{2}{*}{ Construct } & \multirow[b]{2}{*}{ Source } & \multirow[b]{2}{*}{ Sample Item } & \multirow[b]{2}{*}{ Scale Range } & \multirow[b]{2}{*}{ \# Items } & \multicolumn{2}{|c|}{ Coefficient $\omega$} \\
\hline & & & & & Self & Informant \\
\hline Leisure & Siedler et al. 2008 & $\begin{array}{l}\text { "In general, how satisfied } \\
\text { are you with your leisure" }\end{array}$ & $\begin{array}{l}0 \text { (very dissatisfied }) \text { to } 10 \\
(\text { very satisfied })\end{array}$ & 1 & & \\
\hline Friends & Siedler et al. $(2008)$ & $\begin{array}{l}\text { "In general, how satisfied } \\
\text { are you with your friends } \\
\text { and social contacts" }\end{array}$ & $\begin{array}{l}0 \text { (very dissatisfied }) \text { to } 10 \\
\text { (very satisfied })\end{array}$ & 1 & & \\
\hline Family & Siedler et al. (2008) & $\begin{array}{l}\text { "In general, how satisfied } \\
\text { are you with your family } \\
\text { relationships" }\end{array}$ & $\begin{array}{l}0 \text { (very dissatisfied) to } 10 \\
\text { (very satisfied) }\end{array}$ & 1 & & \\
\hline Relationship & Siedler et al. $(2008)$ & $\begin{array}{l}\text { "In general, how satisfied } \\
\text { are you with your partner } \\
\text { relationship" }\end{array}$ & $\begin{array}{l}0 \text { (very dissatisfied) to } 10 \\
\text { (very satisfied) }\end{array}$ & 1 & & \\
\hline $\begin{array}{l}\text { Network Characteristics } \\
\text { \# close friends }\end{array}$ & & & & 1 & & \\
\hline \# friends on Facebook & & & & 1 & & \\
\hline \# persons to discuss & & & & 1 & & \\
\hline $\begin{array}{l}\text { problems with } \\
\text { \# persons to contact for }\end{array}$ & & & & 1 & & \\
\hline $\begin{array}{l}\text { \# persons to contact for } \\
\text { practical help }\end{array}$ & & & & 1 & & \\
\hline $\begin{array}{l}\text { \# persons to ask for } \\
\text { advice }\end{array}$ & & & & 1 & & \\
\hline $\begin{array}{l}\text { Contact frequency with } \\
\text { closest friend }\end{array}$ & & & $\begin{array}{l}\text { once a year (1), every few } \\
\text { months }(2) \text {, once a month } \\
(3), \text { two to three times per } \\
\text { month (4), once a week } \\
(5), \text { several times a week } \\
(6), \text { daily }(7)\end{array}$ & 1 & & \\
\hline
\end{tabular}




\begin{tabular}{|c|c|c|c|c|c|c|}
\hline \multirow[b]{2}{*}{ Construct } & \multirow[b]{2}{*}{ Source } & \multirow[b]{2}{*}{ Sample Item } & \multirow[b]{2}{*}{ Scale Range } & \multirow[b]{2}{*}{ \# Items } & \multirow{2}{*}{\multicolumn{2}{|c|}{ Informant }} \\
\hline & & & & & & \\
\hline $\begin{array}{l}\text { Frequency of joint } \\
\text { activities with friends }\end{array}$ & & & $\begin{array}{l}\text { once a year (1), every few } \\
\text { months (2), once a month } \\
(3), \text { two to three times per } \\
\text { month (4), once a week } \\
(5), \text { several times a week } \\
(6), \text { daily }(7)\end{array}$ & 1 & & \\
\hline
\end{tabular}

Note. Informant-ratings were only collected for the loneliness measures. 
Table S2

Descriptive Statistics

\begin{tabular}{|c|c|c|c|c|c|c|}
\hline \multirow[b]{2}{*}{ Measure } & \multicolumn{3}{|c|}{ Self-Rating } & \multicolumn{3}{|c|}{ Informant-Rating $^{a}$} \\
\hline & M & $\mathrm{SD}$ & $\mathrm{Md}$ & M & $\mathrm{SD}$ & $\mathrm{Md}$ \\
\hline \multicolumn{7}{|l|}{ Loneliness } \\
\hline $\mathrm{RTLS}_{\text {Total }}$ & 2.36 & 0.85 & 2.27 & 2.10 & 0.73 & 2.02 \\
\hline RTLS $_{\text {Emotional }}$ & 2.47 & 0.93 & 2.33 & 2.24 & 0.86 & 2.17 \\
\hline $\operatorname{RTLS}_{\text {Social }}$ & 2.22 & 0.94 & 2.00 & 1.94 & 0.69 & 1.80 \\
\hline $\mathrm{UCLA}_{20 \text { Items }}$ & 2.07 & 0.73 & 1.90 & 1.76 & 0.60 & 1.57 \\
\hline $\mathrm{UCLA}_{3 \text { Items }}$ & 2.60 & 0.85 & 2.67 & 2.27 & 0.76 & 2.17 \\
\hline SI Direct & 2.69 & 1.31 & 2.00 & 2.39 & 1.21 & 2.00 \\
\hline SI Indirect & 2.77 & 1.25 & 2.00 & 2.49 & 1.21 & 2.00 \\
\hline SI Direct ${ }_{\text {Frequency }}$ & 2.60 & 0.95 & 3.00 & 2.43 & 0.79 & 2.42 \\
\hline \multicolumn{7}{|l|}{ Personality } \\
\hline Neuroticism & 4.38 & 1.42 & 4.67 & & & \\
\hline Extraversion & 4.42 & 1.45 & 4.67 & & & \\
\hline Openness & 4.99 & 1.22 & 5.00 & & & \\
\hline Agreeableness & 5.31 & 1.01 & 5.33 & & & \\
\hline Conscientiousness & 5.00 & 1.17 & 5.00 & & & \\
\hline Shyness & 2.85 & 0.71 & 2.80 & & & \\
\hline Sociability & 3.06 & 0.79 & 3.20 & & & \\
\hline Self-Esteem & 3.49 & 0.98 & 3.67 & & & \\
\hline Affiliation Motive & 4.66 & 0.87 & 4.75 & & & \\
\hline Need Frustration & 2.00 & 0.79 & 2.00 & & & \\
\hline Motive $\times$ Need & -0.16 & 0.79 & 0.00 & & & \\
\hline Depressiveness & 2.01 & 0.60 & 1.90 & & & \\
\hline Social Desirability & 1.45 & 0.18 & 1.47 & & & \\
\hline \multicolumn{7}{|l|}{ Satisfaction with... } \\
\hline Life & 6.60 & 2.06 & 7.00 & & & \\
\hline Education & 6.47 & 2.46 & 7.00 & & & \\
\hline Leisure & 6.57 & 2.23 & 7.00 & & & \\
\hline Friends & 6.71 & 2.36 & 7.00 & & & \\
\hline Family & 7.28 & 2.48 & 8.00 & & & \\
\hline Partner Relationship & 8.00 & 1.99 & 8.00 & & & \\
\hline \multicolumn{7}{|c|}{ Network Characteristics } \\
\hline \multicolumn{7}{|c|}{ Number of Friends (Providing). . } \\
\hline Overall & 5.35 & 4.10 & 4.00 & & & \\
\hline on Facebook & 270.84 & 210.93 & 201.50 & & & \\
\hline Help with Problems & 6.82 & 5.92 & 5.00 & & & \\
\hline Instrumental Support & 10.07 & 8.29 & 8.00 & & & \\
\hline Advice & 9.07 & 11.00 & 6.00 & & & \\
\hline \multicolumn{7}{|l|}{ Frequency of. . } \\
\hline Contact & 5.53 & 1.33 & 6.00 & & & \\
\hline Joint Activities & 4.15 & 1.52 & 4.00 & & & \\
\hline
\end{tabular}

Note. ${ }^{a}$ Informant-ratings were only collected for the loneliness measures. RTLS: Rasch-Type Loneliness Scale. UCLA-LS: University of Los Angeles California Loneliness Scale. SI: Single Item. 
Table S3

Zero-Order Correlations

\begin{tabular}{|c|c|c|c|c|c|c|c|c|c|c|c|c|c|c|c|c|c|c|c|c|c|c|c|c|c|c|}
\hline Measure & 1 & 2 & 3 & 4 & 5 & 6 & 7 & 8 & 9 & 10 & 11 & 12 & 13 & 14 & 15 & 16 & 17 & 18 & 19 & 20 & 21 & 22 & 23 & 24 & 25 & 26 \\
\hline \multicolumn{27}{|l|}{ Personality } \\
\hline 1 Neuroticism & & & & & & & & & & & & & & & & & & & & & & & & & & \\
\hline 2 Extraversion & -.21 & & & & & & & & & & & & & & & & & & & & & & & & & \\
\hline 3 Openness & -.04 & .32 & & & & & & & & & & & & & & & & & & & & & & & & \\
\hline 4 Agreeableness & -.03 & .07 & .15 & & & & & & & & & & & & & & & & & & & & & & & \\
\hline 5 Conscientiousness & -.11 & .12 & .12 & .19 & & & & & & & & & & & & & & & & & & & & & & \\
\hline 6 Shyness & .35 & -.68 & -.26 & -.07 & -.15 & & & & & & & & & & & & & & & & & & & & & \\
\hline 7 Sociability & -.13 & .55 & .18 & .31 & .10 & -.34 & & & & & & & & & & & & & & & & & & & & \\
\hline 8 Self-Esteem & -.48 & .30 & .17 & .16 & .27 & -.37 & .21 & & & & & & & & & & & & & & & & & & & \\
\hline 9 Affiliation Motive & .03 & .34 & .15 & .28 & .16 & -.12 & .56 & .11 & & & & & & & & & & & & & & & & & & \\
\hline 10 Need Frustration & .28 & -.33 & -.11 & -.29 & -.11 & .33 & -.32 & -.48 & -.23 & & & & & & & & & & & & & & & & & \\
\hline 11 Motive×Need & -.08 & .10 & .05 & .11 & .06 & -.07 & .12 & .12 & .24 & -.12 & & & & & & & & & & & & & & & & \\
\hline 12 Depressiveness & .57 & -.32 & -.13 & -.23 & -.28 & .36 & -.28 & -.72 & -.19 & .48 & -.15 & & & & & & & & & & & & & & & \\
\hline 13 Social Desirability & -.10 & -.09 & .02 & .36 & .24 & .01 & .10 & .07 & .13 & -.03 & .06 & -.12 & & & & & & & & & & & & & & \\
\hline $\begin{array}{l}\text { Satisfaction with... } \\
14 \text { Life }\end{array}$ & -.33 & .25 & .16 & .15 & .23 & -.28 & .23 & .64 & .22 & -.39 & .17 & -.69 & .02 & & & & & & & & & & & & & \\
\hline 15 Education & -.24 & .16 & .08 & .10 & .26 & -.21 & .16 & .43 & .10 & -.26 & .10 & -.52 & .05 & .60 & & & & & & & & & & & & \\
\hline 16 Leisure & -.25 & .16 & .06 & .11 & .16 & -.15 & .10 & .42 & .16 & -.29 & .10 & -.48 & .05 & .56 & .37 & & & & & & & & & & & \\
\hline 17 Friends & -.21 & .32 & .13 & .20 & .12 & -.29 & .26 & .41 & .31 & -.46 & .14 & -.45 & .00 & .56 & .31 & .56 & & & & & & & & & & \\
\hline 18 Family & -.11 & .15 & .05 & .20 & .18 & -.11 & .21 & .35 & .29 & -.29 & .15 & -.43 & .08 & .51 & .31 & .39 & .49 & & & & & & & & & \\
\hline 19 Partner Relationship & -.03 & .01 & .01 & .09 & .15 & .05 & .06 & .22 & .23 & -.11 & .17 & -.30 & .08 & .48 & .19 & .25 & .33 & .31 & & & & & & & & \\
\hline Network Characteristics & & & & & & & & & & & & & & & & & & & & & & & & & & \\
\hline \multicolumn{27}{|c|}{ Number of Friends (Providing)... } \\
\hline 20 Overall & -.07 & .24 & .13 & .15 & -.02 & -.16 & .30 & .07 & .26 & -.22 & .06 & -.14 & .01 & .12 & .02 & .09 & .28 & .15 & .02 & & & & & & & \\
\hline 21 on Facebook & -.01 & .28 & .09 & .04 & .02 & -.17 & .22 & .03 & .18 & -.08 & .07 & -.02 & -.03 & .07 & .01 & -.08 & .07 & .09 & .02 & .21 & & & & & & \\
\hline 22 Help with Problems & -.09 & .19 & .14 & .15 & .05 & -.17 & .25 & .13 & .21 & -.25 & .03 & -.19 & -.05 & .26 & .08 & .17 & .31 & .24 & -.08 & .37 & .09 & & & & & \\
\hline 23 Instrumental Support & -.17 & .26 & .15 & .17 & .03 & -.21 & .29 & .18 & .23 & -.26 & .05 & -.27 & .04 & .22 & .13 & .17 & .25 & .25 & .07 & .38 & .12 & .51 & & & & \\
\hline 24 Advice & -.04 & .14 & .05 & .09 & .01 & -.07 & .17 & .07 & .09 & -.12 & .03 & -.16 & -.03 & .17 & .08 & .08 & .17 & .17 & .01 & .30 & .13 & .47 & 48 & & & \\
\hline Frequency of... & 01 & & & & & & & & & & & & & & & & & & & & & & & .09 & & \\
\hline $\begin{array}{l}25 \text { Contact } \\
26 \text { Joint Activities }\end{array}$ & $\begin{aligned} .01 \\
-.11\end{aligned}$ & .28 & .17 & .13 & $\begin{array}{l}.01 \\
.04\end{array}$ & $\begin{array}{l}-.08 \\
-.15\end{array}$ & $\begin{array}{l}.21 \\
.37\end{array}$ & $\begin{array}{l}.03 \\
.16\end{array}$ & .39 & $\begin{array}{l}-.13 \\
-.27\end{array}$ & $\begin{array}{l}.06 \\
.12\end{array}$ & $\begin{array}{l}-.10 \\
-.22\end{array}$ & $\begin{array}{l}-.04 \\
-.01\end{array}$ & $\begin{array}{l}.02 \\
.19\end{array}$ & .01 & .23 & .38 & .22 & .02 & .21 & .07 & .27 & .35 & .09 & .52 & \\
\hline
\end{tabular}


Study 2 


\section{Table S4}

Overview of the Measures Used in Study 2

\begin{tabular}{|c|c|c|c|c|c|c|}
\hline \multirow[b]{2}{*}{ Construct } & \multirow[b]{2}{*}{ Source } & \multirow[b]{2}{*}{ Sample Item } & \multirow[b]{2}{*}{ Scale Range } & \multirow[b]{2}{*}{ \# Items } & \multicolumn{2}{|c|}{ Coefficient $\omega$} \\
\hline & & & & & Self & Informant \\
\hline \multicolumn{7}{|c|}{ Demographic Characteristics } \\
\hline Age & & $\begin{array}{l}\text { "Please indicate your } \\
\text { birth year" }\end{array}$ & $\begin{array}{l}\text { Due to the high frequency } \\
\text { of measurement occasions } \\
\text { every three months, we } \\
\text { decided to ask for birth } \\
\text { year so that particiants } \\
\text { were not required to } \\
\text { indicate their age every } \\
\text { three months. Instead, } \\
\text { we calculated age by } \\
\text { subtracting the year of } \\
\text { data collection (e.g., } 2020 \\
\text { for Wave 1) from the } \\
\text { indicated birth year }\end{array}$ & & & \\
\hline Gender & & $\begin{array}{l}\text { "Please indicate your } \\
\text { gender" }\end{array}$ & $\begin{array}{l}1 \text { (male), } 2 \text { (female), } 3 \\
\text { (diverse); for the analysis } \\
\text { reported in the } \\
\text { mansucript, the variable } \\
\text { was recoded as } 1 \text { (female) } \\
\text { and } 0 \text { (not female, incl. } \\
\text { male and diverse) }\end{array}$ & & & \\
\hline
\end{tabular}


Relationship Duration

Loneliness

Rasch-Type Loneliness

Scale $\left(\right.$ RTLS $\left._{\text {Total }}\right)$ de Jong Gierveld and van Tilburg (2006)
Scale Range

Coefficient $\omega$

"Please select your

highest educational

(Grundschule - Primary

degree"

School), 3 (Hauptschul

ndary modern

school qualification), 4

(Realschule - secondary

school certificate), 5

(Fachhochschulreife -

entrance qualification for

a university of applied

sciences), 6 (Abitur -

university entrance

qualification), 7

(Hochschulstudium -

university degree, e.g.,

B.Sc., M.Sc.), 8

(Promotion - PhD)

"How long have you been involved in the

participants could enter a number in a numeric field

and select whether they

refer to weeks, months, or

years; for the analysis

reported in the

mansucript, we

transformed relationship

duration to years

1 (does not apply) to 5 


\begin{tabular}{|c|c|c|c|c|c|}
\hline $\begin{array}{l}\text { Direct Single Item (SI } \\
\text { Direct) }{ }^{a}\end{array}$ & & $\begin{array}{l}\text { lack companionship" } \\
\text { "I feel lonely" }\end{array}$ & $\begin{array}{l}1 \text { (does not at all apply) } \\
\text { to } 5 \text { (does fully apply) }\end{array}$ & 1 & \\
\hline \multicolumn{6}{|l|}{ Personality } \\
\hline Neuroticism & $\begin{array}{l}\text { Rammstedt et al. } \\
(2020)\end{array}$ & "I worry a lot" & $\begin{array}{l}1 \text { (do not agree at all) to } \\
5 \text { (fully agree) }\end{array}$ & 3 & .74 \\
\hline Extraversion & Rammstedt et al. & "I tend to take the lead" & $\begin{array}{l}1 \text { (do not agree at all) to } \\
5 \text { (fully agree) }\end{array}$ & 3 & .52 \\
\hline Openness & Rammstedt et al. & $\begin{array}{l}\text { "I can get excited about } \\
\text { art, music and literature" }\end{array}$ & $\begin{array}{l}1 \text { (do not agree at all) to } \\
5 \text { (fully agree) }\end{array}$ & 3 & .41 \\
\hline Agreeableness & Rammstedt et al. & $\begin{array}{l}\text { "I am compassionate, } \\
\text { have a soft heart." }\end{array}$ & $\begin{array}{l}1 \text { (do not agree at all) to } \\
5 \text { (fully agree) }\end{array}$ & 3 & .50 \\
\hline Conscientiousness & Rammstedt et al. & $\begin{array}{l}\text { "I see myself as someone } \\
\text { who does things } \\
\text { effectively" }\end{array}$ & $\begin{array}{l}1 \text { (do not agree at all) to } \\
5 \text { (fully agree) }\end{array}$ & 3 & .641 \\
\hline Self-Esteem & $\begin{array}{l}\text { von Collani and } \\
\text { Herzberg }(2003)\end{array}$ & $\begin{array}{l}\text { "I like myself just the } \\
\text { way I am" }\end{array}$ & $\begin{array}{l}1 \text { (do not agree at all) to } \\
5 \text { (fully agree) }\end{array}$ & 10 & .92 \\
\hline
\end{tabular}




\begin{tabular}{|c|c|c|c|c|c|c|}
\hline \multirow[b]{2}{*}{ Construct } & \multirow[b]{2}{*}{ Source } & \multirow[b]{2}{*}{ Sample Item } & \multirow[b]{2}{*}{ Scale Range } & \multirow[b]{2}{*}{ \# Items } & \multicolumn{2}{|c|}{ Coefficient $\omega$} \\
\hline & & & & & Self & Informant \\
\hline Depressiveness & $\begin{array}{l}\text { Spaderna et al. } \\
(2002)\end{array}$ & $\begin{array}{l}\text { "In general, how often do } \\
\text { you feel sad" }\end{array}$ & $\begin{array}{l}1 \text { (almost never) to } 4 \\
\text { (almost always) }\end{array}$ & 5 & .87 & \\
\hline Affiliation Motive & $\begin{array}{l}\text { Schönbrodt and } \\
\text { Gerstenberg }(2012)\end{array}$ & $\begin{array}{l}\text { "How important is it for } \\
\text { you to be in the company } \\
\text { of friends?" }\end{array}$ & $\begin{array}{l}1 \text { (not important) to } 6 \\
\text { (very important) }\end{array}$ & 2 & .68 & \\
\hline Shyness & $\begin{array}{l}\text { Asendorpf and } \\
\text { Wilpers }(1998)\end{array}$ & $\begin{array}{l}\text { "I feel inhibited when I } \\
\text { am with other people" }\end{array}$ & $\begin{array}{l}1 \text { (does not apply) to } 5 \\
\text { (applies fully) }\end{array}$ & 5 & .74 & \\
\hline Sociability $^{b}$ & $\begin{array}{l}\text { Asendorpf and } \\
\text { Wilpers (1998) }\end{array}$ & $\begin{array}{l}\text { "I really like to talk to } \\
\text { other people" }\end{array}$ & $\begin{array}{l}1 \text { (does not apply) to } 5 \\
\text { (applies fully) }\end{array}$ & 5 & .68 & \\
\hline Satisfaction & & & & & & \\
\hline Life & Siedler et al. 2008 & $\begin{array}{l}\text { "In general, how satisfied } \\
\text { are you with your life" }\end{array}$ & $\begin{array}{l}0 \text { (very dissatisfied }) \text { to } 10 \\
\text { (very satisfied })\end{array}$ & 1 & & \\
\hline Education & Siedler et al. 2008) & $\begin{array}{l}\text { "In general, how satisfied } \\
\text { are you with your } \\
\text { education and work life" }\end{array}$ & $\begin{array}{l}0 \text { (very dissatisfied }) \text { to } 10 \\
\text { (very satisfied) }\end{array}$ & 1 & & \\
\hline Leisure & Siedler et al. 2008 & $\begin{array}{l}\text { "In general, how satisfied } \\
\text { are you with your leisure" }\end{array}$ & $\begin{array}{l}0 \text { (very dissatisfied) to } 10 \\
\text { (very satisfied) }\end{array}$ & 1 & & \\
\hline Friends & Siedler et al. $(2008)$ & $\begin{array}{l}\text { "In general, how satisfied } \\
\text { are you with your friends } \\
\text { and social contacts" }\end{array}$ & $\begin{array}{l}0(\text { very dissatisfied }) \text { to } 10 \\
\text { (very satisfied) }\end{array}$ & 1 & & \\
\hline Family & Siedler et al. 2008) & $\begin{array}{l}\text { "In general, how satisfied } \\
\text { are you with your family } \\
\text { relationships" }\end{array}$ & $\begin{array}{l}0 \text { (very dissatisfied }) \text { to } 10 \\
\text { (very satisfied) }\end{array}$ & 1 & & \\
\hline Relationship & $\begin{array}{l}\text { Sander and Böcker } \\
1993\end{array}$ & $\begin{array}{l}\text { "In general, how satisfied } \\
\text { are you with your partner } \\
\text { relationship" }\end{array}$ & $\begin{array}{l}0 \text { (very dissatisfied) to } 5 \\
\text { (very satisfied) }\end{array}$ & 7 & .81 & \\
\hline
\end{tabular}
was only assessed at Waves 1 through 3 (i.e., Janury 2020 until July 2020). 


\section{Table S5}

Descriptive Statistics

\begin{tabular}{|c|c|c|c|c|c|c|}
\hline \multirow[b]{2}{*}{ Measure } & \multicolumn{3}{|c|}{ Self-Rating } & \multicolumn{3}{|c|}{ Informant-Rating $^{a}$} \\
\hline & M & $\mathrm{SD}$ & Md & M & $\mathrm{SD}$ & Md \\
\hline \multicolumn{7}{|l|}{ Loneliness } \\
\hline $\operatorname{RTLS}_{\text {Total }}$ & 2.07 & 0.72 & 2.00 & 2.30 & 0.76 & 2.17 \\
\hline $\operatorname{RTLS}_{\text {Emotional }}$ & 2.21 & 0.87 & 2.00 & 2.39 & 0.87 & 2.33 \\
\hline $\operatorname{RTLS}_{\text {Social }}$ & 1.93 & 0.82 & 2.00 & 2.21 & 0.90 & 2.00 \\
\hline $\mathrm{UCLA}_{8 \text { Items }}$ & 1.98 & 0.60 & 1.88 & 2.13 & 0.67 & 2.00 \\
\hline $\mathrm{UCLA}_{3 \text { Items }}$ & 2.22 & 0.74 & 2.00 & 2.32 & 0.79 & 2.33 \\
\hline SI Direct & 1.69 & 0.89 & 1.00 & 1.99 & 1.02 & 2.00 \\
\hline \multicolumn{7}{|l|}{ Personality } \\
\hline Neuroticism & 2.88 & 0.90 & 2.67 & & & \\
\hline Extraversion & 3.10 & 0.70 & 3.00 & & & \\
\hline Openness & 3.78 & 0.68 & 3.67 & & & \\
\hline Agreeableness & 3.67 & 0.72 & 3.67 & & & \\
\hline Conscientiousness & 3.36 & 0.77 & 3.33 & & & \\
\hline Shyness & 2.82 & 0.63 & 2.80 & & & \\
\hline Sociability & 3.09 & 0.68 & 3.20 & & & \\
\hline Self-Esteem & 3.31 & 0.81 & 3.50 & & & \\
\hline Affiliation Motive & 4.05 & 0.95 & 4.00 & & & \\
\hline Depressiveness & 1.81 & 0.57 & 1.80 & & & \\
\hline \multicolumn{7}{|l|}{ Satisfaction with... } \\
\hline Life & 7.16 & 2.10 & 8.00 & & & \\
\hline Education & 6.49 & 2.73 & 7.00 & & & \\
\hline Leisure & 6.58 & 2.49 & 7.00 & & & \\
\hline Friends & 7.14 & 2.39 & 8.00 & & & \\
\hline Family & 7.34 & 2.61 & 8.00 & & & \\
\hline Partner Relationship & 4.43 & 0.47 & 4.57 & & & \\
\hline
\end{tabular}

Note. ${ }^{a}$ Informant-ratings were only collected for the loneliness measures. RTLS: Rasch-Type Loneliness Scale. UCLA-LS: University of Los Angeles California Loneliness Scale. SI: Single Item. 


\section{Table S6}

\begin{tabular}{|c|c|c|c|c|c|c|c|c|c|c|c|c|c|c|c|c|}
\hline Measure & 1 & 2 & 3 & 4 & 5 & 6 & 7 & 8 & 9 & 10 & 11 & 12 & 13 & 14 & 15 & 16 \\
\hline \multicolumn{17}{|l|}{ Personality } \\
\hline \multicolumn{17}{|l|}{1 Neuroticism } \\
\hline 2 Extraversion & -.14 & & & & & & & & & & & & & & & \\
\hline 3 Openness & .01 & .14 & & & & & & & & & & & & & & \\
\hline 4 Agreeableness & -.11 & -.02 & .10 & & & & & & & & & & & & & \\
\hline 5 Conscientiousness & -.15 & .21 & -.03 & .10 & & & & & & & & & & & & \\
\hline 6 Shyness & .25 & -.53 & -.13 & -.06 & -.10 & & & & & & & & & & & \\
\hline 7 Sociability & -.08 & .34 & .04 & .25 & .03 & -.29 & & & & & & & & & & \\
\hline 8 Self-Esteem & -.63 & .24 & .06 & .14 & .24 & -.29 & .11 & & & & & & & & & \\
\hline 9 Affiliation Motive & -.08 & .37 & .04 & .24 & .08 & -.22 & .66 & .13 & & & & & & & & \\
\hline 10 Depressiveness & .70 & -.24 & .08 & -.15 & -.18 & .27 & -.17 & -.66 & -.16 & & & & & & & \\
\hline \multicolumn{17}{|l|}{ Satisfaction with... } \\
\hline 11 Life & -.36 & .19 & .02 & .17 & .15 & -.19 & .09 & .48 & .11 & -.45 & & & & & & \\
\hline 12 Education & -.33 & .16 & .01 & .11 & .19 & -.14 & .08 & .42 & .13 & -.40 & .61 & & & & & \\
\hline 13 Leisure & -.30 & .17 & .05 & .05 & .09 & -.16 & .07 & .31 & .09 & -.35 & .54 & .39 & & & & \\
\hline 14 Friends & -.25 & .20 & .02 & .10 & .10 & -.22 & .08 & .31 & .17 & -.34 & .56 & .34 & .62 & & & \\
\hline 15 Family & -.22 & .11 & -.05 & .13 & .06 & -.11 & .09 & .24 & .08 & -.29 & .46 & .29 & .37 & .44 & & \\
\hline 16 Partner Relationship & -.16 & .04 & .05 & .13 & .10 & -.06 & -.02 & .21 & .00 & -.26 & .26 & .09 & .15 & .25 & .16 & \\
\hline
\end{tabular}


Study 3 
Table S7

Descriptive Statistics

\begin{tabular}{|c|c|c|c|c|c|c|c|c|c|}
\hline \multirow[b]{2}{*}{ Measure } & \multicolumn{3}{|c|}{ Time 1} & \multicolumn{3}{|c|}{ Time 2} & \multicolumn{3}{|c|}{ Time 3} \\
\hline & M & SD & Md & M & SD & Md & M & SD & Md \\
\hline SI Direct & 2.57 & 1.24 & 2.00 & 2.42 & 1.23 & 2.00 & 2.41 & 1.20 & 2.00 \\
\hline SI Indirect & 2.60 & 1.23 & 2.00 & 2.50 & 1.21 & 2.00 & 2.52 & 1.20 & 2.00 \\
\hline SI Direct ${ }_{\text {Frequency }}$ & 2.59 & 1.00 & 3.00 & 2.59 & 1.01 & 3.00 & 2.57 & 0.99 & 3.00 \\
\hline
\end{tabular}

Note. SI: Single Item 


\section{References}

Asendorpf, J. B., \& Wilpers, S. (1998). Personality effects on social relationships. Journal of Personality and Social Psychology, 74, 1531-1544. https://doi.org/ 10.1037/0022-3514.74.6.1531

Chen, B., Vansteenkiste, M., Beyers, W., Boone, L., Deci, E. L., van der Kaap-Deeder, J., Duriez, B., Lens, W., Matos, L., Mouratidis, A., Ryan, R. M., Sheldon, K. M., Soenens, B., van Petegem, S., \& Verstuyf, J. (2015). Basic psychological need satisfaction, need frustration, and need strength across four cultures. Motivation and Emotion, 39, 216-236. https://doi.org/10.1007/s11031-0149450-1

de Jong Gierveld, J., \& Kamphuis, F. H. (1985). The development of a Rasch-type loneliness scale. Applied Psychological Measurement, 9, 289-299. https://doi. org/10.1177/014662168500900307

de Jong Gierveld, J., \& van Tilburg, T. (2006). A 6-item scale for overall, emotional, and social loneliness: Confirmatory tests on survey data. Research on Aging, 28, 582-598. https://doi.org/10.1177/0164027506289723

Döring, N., \& Bortz, J. (1993). Psychometrische Einsamkeitsforschung: Deutsche Neukonstruktion der UCLA Loneliness Scale [Psychometric research on loneliness: German version of the UCLA loneliness scale]. Diagnostica, 39, 224239.

Hahn, E., Gottschling, J., \& Spinath, F. M. (2012). Short measurement of personality: Validity and reliability of the GSOEP Big Five Inventory (BFI-S). Journal of Research in Personality, 46, 355-359. https://doi.org/10.1016/j.jrp.2012.03. 008

Hawkley, L. C., Duvoisin, R., Ackva, J., Murdoch, J. C., \& Luhmann, M. (2015). Loneliness in older adults in the USA and Germany: Measurement invariance and validation. Working Paper Series, NORC at the University of Chicago, Paper 2015-002.

Rammstedt, B., Danner, D., Soto, C. J., \& John, O. P. (2020). Validation of the short and extra-short forms of the Big Five Inventory-2 (BFI-2) and their German adaptations. European Journal of Psychological Assessment, 36(1), 149-161. https://doi.org/10.1027/1015-5759/a000481

Sander, J., \& Böcker, S. (1993). Die deutsche Form der Relationship Assessment Scale (RAS) [The German version of the Relationship Assessment Scale (RAS): A short scale for measuring satisfaction in a dyadic relationship]. Diagnostica, 39, 55-62.

Schönbrodt, F. D., \& Gerstenberg, F. X. R. (2012). An IRT analysis of motive questionnaires: The Unified Motive Scales. Journal of Research in Personality, 46 (6), 725-742. https://doi.org/10.1016/j.jrp.2012.08.010

Siedler, T., Schupp, J., Spiess, K. C., \& Wagner, G. G. (2008). The German SocioEconomic Panel as reference data set. RatSWD Working Paper, 48. https: //doi.org/10.2139/ssrn.1445341 
Spaderna, H., Schmukle, S. C., \& Krohne, H. W. (2002). Bericht über die deutsche Adaption der State-Trait Depression Scales (STDS) [Report about the German adaptation of the State-Trait Depression Scale (STDS)]. Diagnostica, 48, 8089. https://doi.org/10.1026//0012-1924.48.2.80

Stöber, J. (2001). The Social Desirability Scale-17 (SDS-17): Convergent validity, discriminant validity, and relationship with age. European Journal of Psychological Assessment, 17(3), 222-232. https://doi.org/10.1027//1015-5759.17.3.222.

von Collani, G., \& Herzberg, P. Y. (2003). Eine revidierte Fassung der deutschsprachigen Skala zum Selbstwertgefühl von Rosenberg [A revised version of the German adaptation of the Rosenberg Self-Esteem Scale]. Zeitschrift für Differentielle und Diagnostische Psychologie, 24(1), 3-7. 